\title{
THE LEARNING CURVE IN A COMPETITIVE INDUSTRY
}

\author{
Emmanuel Petrakis, Eric Rasmusen and Santanu Roy*
}

\begin{abstract}
We consider the learning curve in an industry with free entry and exit, and price-taking firms. A unique equilibrium exists if the fixed cost is positive. While equilibrium profits are zero, mature firms earn rents on their learning, and, if costs are convex, no firm can profitably enter after the date the industry begins. Under some cost and demand conditions, however, firms may have to exit the market despite their experience gained earlier. Furthermore identical firms facing the same prices may produce different quantities. The market outcome is always socially efficient, even if dictates that firms exit after learning. Finally, actual and optimal industry concentration does not always increase in the intensity of learning.
\end{abstract}

Keywords

Learning curve, Industry evolution, Perfect competition.

* Emmanuel Petrakis, Departamento de Economía, Universidad Carlos III de Madrid, Calle Madrid 126, 28903 Getafe (Madrid), Spain, e-mail: petrakis@elrond.uc3m.es; Eric Rasmusen, Indiana University School of Business, 10th Street and Fee Lane, Bloomington, Indiana, USA 47405-1701, e-mail: erasmuse@indiana.edu; Santanu Roy, Econometric Institute, Erasmus University, POBox 1738, 3000 DR Rotterdam, The Netherlands, e-mail: santanu@wke.few.eur.nl. 


\title{
The Learning Curve in a Competitive Industry
}

\author{
May 27, 1994 \\ Emmanuel Petrakis, Eric Rasmusen, and Santanu Roy
}

\begin{abstract}
We consider the learning curve in an industry with free entry and exit, and pricetaking firms. A unique equilibrium exists if the fixed cost is positive. While equilibrium profits are zero, mature firms earn rents on their learning, and, if costs are convex, no firm can profitably enter after the date the industry begins. Under some cost and demand conditions, however, firms may have to exit the market despite their experience gained earlier. Furthermore identical firms facing the same prices may produce different quantities. The market outcome is always socially efficient, even if it dictates that firms exit after learning. Finally, actual and optimal industry concentration does not always increase in the intensity of learning.
\end{abstract}

Petrakis: Departamento de Economia, Universidad Carlos III de Madrid, Calle Madrid 12628903 Getafe (Madrid) Spain. Fax: 341-624-9875. Phone: 341624-9652. Internet: Petrakis@eco.uc3m.es.

Rasmusen: Indiana University School of Business, 10th Street and Fee Lane, Bloomington, Indiana, U.S.A 47405-1701. Phone: (812) 855-9219. Fax: (812) 855-8679. Internet: Erasmuse Oindiana.edu.

Roy: Econometric Institute, Erasmus University, P.O.Box 1738, 3000 DR Rotterdam, The Netherlands. Fax: 31-10-452-7746. Phone: 31-10-408-1420. Internet: Santanu Owke.few.eur.nl.

Keywords: Learning curve, industry evolution, perfect competition.

We would like to thank Tai-Yeong Chung and seminar participants at Notre Dame, Tilburg University, the University of Southern California, the University of Western Ontario, the 1992 European Econometric Society Meetings, the Seventh Annual Congress of the European Economic Association, and the ASSET Meetings in Toulouse for their comments. John Spence provided research assistance. This 
work was begun at the University of California, Los Angeles. This is the working paper version of this article. 


\section{Introduction}

Economists have long been aware that a firm's cost curve for producing a given item may shift down over time as learning occurs. The plot of the cost level against cumulative output is known as the learning curve or experience curve. Our subject here is learning in an industry of price-taking firms with free entry and exit. An arbitrarily large measure of firms with identical technologies compete in a homogeneous industry. Each firm's cost curve shifts down with its own accumulated experience in production, measured by its cumulative output.

The assumption of a perfectly competitive market structure distinguishes our model from much of the existing literature on learning-by-doing, which has focussed on monopoly and oligopoly. ${ }^{1}$ If the average cost at any point of time is constant in current output, then learning introduces an intertemporal economy of scale that creates a natural monopoly. This need not be the case, however, if the technology displays sufficient decreasing returns. In that case, learning does not lead to a natural monopoly and is, in fact, compatible with perfect competition. Learning-by-doing is distinct from increasing returns to scale in this sense. ${ }^{2}$

Our model is not part of that branch of the learning literature which studies industries in which an individual firm's experience spills over to other firms in the industry (e.g., Arrow [1962], Ghemawat \& Spence [1985], Romer [1986], Lucas [1988], and Stokey [1986, 1988]). While the market structure in these models is competitive, the presence of learning spillovers gives rise to decreasing-cost industries as distinct from decreasing-cost firms. We exclude

\footnotetext{
'See Spence (1981), Clarke, Darrough \& Heineke (1982), Fudenberg \& Tirole (1983), Smiley \& Ravid (1983), Bhattacharya (1984), Dasgupta \& Stiglitz (1988), Jovanovic \& Lach (1989), Mookherjee \& Ray (1991), and Cabral \& Riordan (1991).

${ }^{2}$ See Mookherjee \& Ray (1992) for a discussion of other differences between increasing returns to scale and learning-by-doing.
} 
such spillovers, and consider only firm-specific learning-by-doing.

Our point of departure is the model of Fudenberg \& Tirole (1983), which considers learning-by-doing in a competitive industry with constant instantaneous marginal cost. In their setting, learning-by-doing is incompatible with perfect competition, but we will come to a different conclusion, because we specify a different cost function. We analyze an industry with the usual textbook assumption of increasing marginal cost, not constant marginal cost, and show that in a two-period model with a fixed cost, a unique perfectly competitive equilibrium exists. With no fixed cost, on the other hand, an infinite number of firms enter the industry, each producing an infinitesimal output, and no learning takes place; the possibility of learning is irrelevant.

If we make the stronger assumption that costs are convex, then the unique equilibrium takes one of two forms, depending on the demand and cost parameters of the economic environment. Whatever the environment, no firm can profitably enter after the date at which the industry begins. In the first type of environment, all firms that enter remain in the industry permanently. The equilibrium discounted stream of profits is zero, but mature firms earn quasi-rents on their learning, compensating for their losses in the first period.

In the second type of environment, some firms exit, because the mature industry cannot sustain the original number of firms with non-negative profits. Firms initially identical, facing the same prices, produce different quantities of the homogeneous good in the first period, and some of them will exit in the second period. Relatively inelastic demand coupled with a strong learning effect gives rise to this outcome, which is an example of the "shakeout" that Hopenhayn (1993) discusses in a similar context.

Surprisingly, the equilibrium is socially efficient whether it includes exit or not. Even in the equilibrium with exit, a social planner would choose the 
same number of firms of each type, the same quantity produced by each firm in each period, and the same prices as in the competitive equilibrium. Thus, the presence of learning-by-doing implies neither the usefulness of a government industrial policy to ensure optimal learning, nor the useful effects of large, innovative monopolies so often attributed to Schumpeter (1950). Our model will uncover a pitfall that may exist for antitrust and regulatory authorities. Although all firms in our model are price-takers, one possible feature of equilibrium is that prices are sometimes below marginal cost, sometimes above marginal cost, that profits rise over time, small firms drop out of the market and large firms expand even further, and that the large firms increase their profits from negative to positive levels without any new entry occuring. This may set off more than one antitrust alarm bell, but government intervention is not only unnecessary, but possibly harmful.

Section II describes the model and discusses its assumptions. Section III presents theorems on existence and efficiency of the competitive equilibrium, and discusses the pattern of entry and exit. Section IV characterizes the equilibrium under the assumption of convex costs. Section $V$ contains a numerical example and looks into special cases where (a) learning reduces only the fixed cost, not the variable cost of production, and (b) learning reduces just the marginal cost, not the fixed cost. Section VI concludes.

\section{The Model}

An arbitrarily large measure of initially identical firms compete to enter in a homogeneous industry. The measure of firms actually operating is determined by free entry and exit. Each firm is a price taker, since it is infinitesimal compared to the industry. ${ }^{3}$ Firms are indexed by $i$. Time is

\footnotetext{
${ }^{3}$ Modelling perfect competition requires the use of a continuum of firms, since each firm must exert an infinitesimal influence on the market. If firms are of finite size, they are not profit-maximizing if they (a) take prices as given, and (b) ignore the possibility
} 
discrete, and the market lasts for two periods. Firm $i$ produces output $q_{t}(i)$ in period $t, t=1,2$.

Each firm $i$ faces the same current total cost at time $t$ as a function of its current output $q_{t}(i)$ and its experience $x_{t}(i)$ :

$$
C\left(g_{t}(i), x_{t}(i)\right),
$$

where $x_{t}(i)$ is firm $i$ 's cumulative output before time $t, s 0$ that $x_{1}(i)=0$ and $x_{2}(i)=q_{1}(i)$. Let

$$
f\left(q_{1}, q_{2}\right)=C\left(q_{1}, 0\right)+\delta C\left(q_{2}, q_{1}\right),
$$

where $\delta \in[0,1]$ is the discount factor, so $f$ represents a firm's discounted sum of production costs across the two periods.

If amount $n$ of firms are active, industry output is $Q_{t}=\int_{0}^{n} q_{t}(i) d i$. The market demand function, $D(p)$, is the same in both periods and is separable across time. Let $P(Q)$ be the inverse demand function. Define $p_{m}$ as the minimum average cost at zero experience, so

$$
p_{m}=\min _{q \geq 0}[C(q, 0) / q] \text {. }
$$

Denote the minimum efficient scale at zero experience by $q_{m}$, so

$$
q_{m} \in \underset{q \geq 0}{\operatorname{argmin}}[C(q, 0) / q]
$$

Note that $C(q, x)$ is a mapping from $\mathrm{R}_{+}^{2}$ into $\mathrm{R}_{+}, P(Q)$ is a mapping from $\mathbf{R}_{+}$into $\mathbf{R}_{+}$, the partial derivative $C_{q}$ is the current marginal cost, and the partial derivative $C_{z}$ is the marginal benefit from learning at some particular output level.

We impose the following six assumptions on costs and demand:

that their entry might drive industry profits negative. Other learning articles which use price-taking firms include Fudenberg \& Tirole (1983), Boldrin \& Scheinkman (1988), and Majd \& Pindyck (1989). 
(A1) [Smoothness] $C(q, x)$ is continuously differentiable on $\mathbf{R}_{+}^{2}$.

(A2) [The Cost Function] $C_{q}(q, x)>0$ for $q>0$ and $x \geq 0 ; C_{x}(q, x) \leq 0$ for all $(q, x) \in \mathrm{R}_{+}^{2}$ and $C_{\varepsilon}(q, x)<0$ for all $(q, x) \in(0, K] \times[0, K]$, where $K$ is defined in (A5).

(A3) [The Fixed Cost] For any $q>0$ and $x \geq 0, C(q, x)>0$; Also, $C(0,0)>$ 0 .

(A4) [Demand Function] $P$ is continuous and strictly decreasing; $P^{\prime}(Q)<0$ for all $Q>0$ and $P(Q) \rightarrow 0$ as $Q \rightarrow+\infty$.

(A5) [Eventual Strong Decreasing Returns] There exists $K>0$ such that the following holds: if either $q_{1}>K$ or $q_{2}>K$ (or both), then there exist $\alpha$ and $\beta \in[0,1]$ such that

$$
f\left(q_{1}, q_{2}\right)>f\left(\alpha q_{1}, \beta q_{2}\right)+f\left((1-\alpha) q_{1},(1-\beta) q_{2}\right) .
$$

(A6) [Non-trivial model] $P(0)>p_{m}$.

Assumption (Al) guarantees the continuity of the marginal cost and marginal benefit functions.

Assumption (A2) says that the marginal cost is always positive, that greater experience never increases the total cost, and that greater experience strictly reduces the total cost of producing any amount from 0 to the amount $K$ where a firm becomes inefficiently large.

The total production cost, not just the marginal cost, is nonincreasing in the amount of accumulated experience. Figure 1 shows one cost function that

\footnotetext{
${ }^{4}$ Instead of $C_{z}(q, x)<0$, we could assume that $C(q, x)<C(q, 0)$ for all $x>0$, i.e., that the cost of producing a positive amount is lower with some experience than with no experience. This would lead to a slight weakening of our characterization of equilibrium. (See footnote 6 below.)
} 
satisfies the assumptions - the cost function which will be Example 2 later in the article. Note the increasing marginal costs for any level of learning, and the decreasing returns to learning, for any level of output.

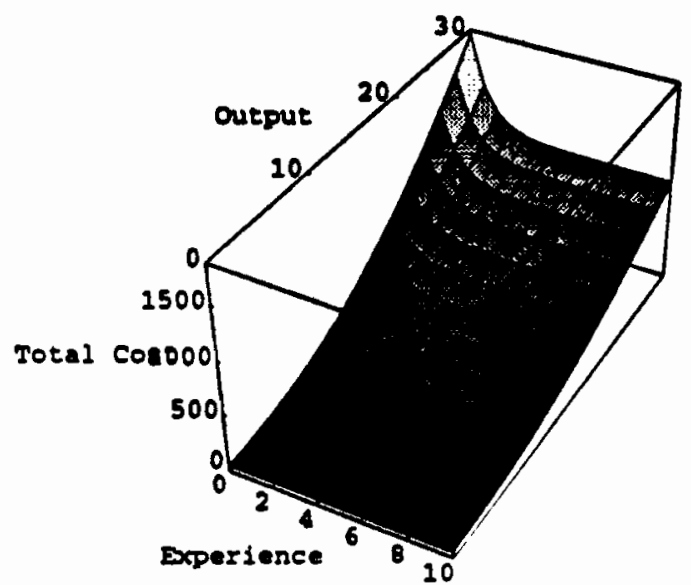

Figure 1: A Firm's Total Cost as a Function of Output and Experience

Assumption (A3) says that there is a fixed cost to production and that positive production is always costly. This assumption allows the fixed cost to become zero even with a very small amount of experience, however, so it allow's for an approximation of the case of no fixed cost except for a onceand-for-all entry cost.

Assumption (A4) says that the demand curve slopes down, that the quantity demanded goes to infinity as the price goes to zero (i.e., demand is insatiable).

Assumption (A5) says that if, in any period, output produced by a 
firm is too large, it is possible to have two firms produce the same output vector at a lower total cost. This prevents the industry from being a natural monopoly. ${ }^{5}$

Assumption (A6) places restrictions on the demand and cost functions jointly to ensure existence of a nondegenerate equilibrium. If $P(0)$ were allowed to take any value, no matter how small, then the equilibrium might be at zero output for every firm.

The six assumptions listed above are all that are needed for our main results, but with a little more structure on the model we can strengthen the results further. We will do that in Section $\mathrm{N}$ by adding the following assumption, which is not implied by (A1)-(A6):

(A7) [Convex Costs] $C$ is convex; for all $x \geq 0, C(g, x)$ is strictly convex in $q$, and for all $q \geq 0$, if $x_{1}>x_{2}$, then $C_{q}\left(q, x_{1}\right) \leq C_{q}\left(q, x_{2}\right)$.

Assumption (A7) requires the total cost function to be convex in $x$ and q. For any level of experience, the current marginal cost is strictly increasing in current output. Assumption (A7) is sufficient to ensure strict convexity of $f$ on $\mathbf{R}_{+}^{2}$. Part of this assumption is that $C_{x}$ is nondecreasing in $x$; that is, there are decreasing returns to learning at any given level of current output. Assumption (A7) is not necessary for existence, uniqueness, and optimality of equilibrium prices and so will not be used for Propositions 1 and 2.

\footnotetext{
${ }^{5}$ If one thinks in terms of multiproduct firms, (A5) requires that the joint cost of production is no longer subadditive if the firm produces an excessive amount of the two goods (see Panzar [1989]). Note, incidentally, that the crucial difference between a learning model and a static model of joint production is time consistency: in our learning model we will require that second-period profits be non-negative (or no firms would operate in the second period), whereas in static joint production, profits on either one of the goods can be negative.
} 
Our specification of the cost function allows a firm to accumulate experience on both its fixed and marginal costs. Each firm maximizes its discounted stream of profits, taking prices as given. An active firm exits the industry in the second period if its profits from that time on would be negative. $A$ firm with no experience enters the industry in the second period only if it can make positive profits in that period.

\section{Properties of the Competitive Equilibrium}

Let $p_{t}$ be the market price in period $t$. Denote firms that stay in the market for both periods as staying or S-type firms, with output $q_{t}$ in period $t$, flow profit $\pi_{t}$, and total profits of $\Pi$, discounted back to time of entry. Denote firms that exit at the end of the first period as exiting or E-type firms, with output $q_{E}$ and profit $\pi_{E}$. Denote firms that enter the industry at the beginning of the second period as late-entering or L-type firms, with output $q_{L}$ and profit $\pi_{L}$ in the second period (not discounted back to the first period). Finally, let $n_{S}, n_{E}$, and $n_{L}$ be the measures of active firms of each type.

A firm staying in the industry for both periods maximizes its discounted sum of profits. The first order conditions for the frm's profit maximization problem are:

$$
\begin{array}{r}
p_{1}=C_{q}\left(q_{1}, 0\right)+\delta C_{z}\left(q_{2}, q_{1}\right) \\
p_{2}=C_{q}\left(q_{2}, q_{1}\right) .
\end{array}
$$

Equation (1) says that as long as learning still occurs, a staying firm will choose output in the first period so that its marginal cost is greater than the market price, since $C_{x}\left(q_{2}, q_{1}\right)$ is negative. In other words, a staying firm overproduces in the first period in order to reduce its cost in the second period. As a result, a staying firm makes losses initially in equilibrium, which are 
counterbalanced by positive gains later. Equation (2) is the standard "price equals marginal cost" condition. If the market ends in the second period, any further learning is of no use to a staying firm, 80 a firm maximizing profits from that time on chooses output to equate price to its marginal cost.

Marginal cost in the standard model is here replaced by what one might call the Effective Marginal Cost. the increase in lifetime discounted costs when current output increases, which for the first period is $C_{q}\left(q_{1}, 0\right)+$ $\delta C_{x}\left(q_{2}, q_{1}\right)$. A price-taking firm which maximizes profits in a dynamic context chooses its output to equate price to its effective marginal cost in period 1. A firm's effective marginal cost in period 2 is just its marginal cost. Note that the effective marginal cost comes arbitrarily close to the marginal cost of a non-experienced firm for sufficiently large $q_{1}$, because if a firm produces too much today, its marginal benefit from learning becomes almost zero.

An equilibrium should be characterized by rational price-taking behavior on the part of firms, but rationality and price taking do not necessarily result in identical behavior by all firms. We define equilibrium as follows.

Definition: An equilibrium consists of variables defined in (a) through (d) which satisfy conditions (i) through (xi) below.

(a) Measures ( $\left.n_{S}, n_{E}, n_{L}\right)$ of type $S, E$ and $L$ firms who enter the market.

(b) Functions $q_{1}(i)$ and $q_{2}(i)$, where $q_{j}:\left[0, n_{s}\right] \rightarrow \mathbf{R}_{+}, j=$ $1,2, q_{j}($.$) integrable (with respect to Lebesgue measure); q_{j}(i)$ is the output produced by firm $i$ of S-type in period $j$.

(c) Functions $q_{E}:\left[0, n_{E}\right] \rightarrow \mathbf{R}_{+}$and $q_{L}:\left[0, n_{L}\right] \rightarrow \mathbf{R}_{+}$, integrable, where $q_{E}(i)$ and $q_{L}(j)$ are the output produced by the $i$-th $E$ and $j$-th $\mathrm{L}$ type firms in their periods in the market.

(d) Prices $p_{1} \geq 0$ and $p_{2} \geq 0$.

The variables defined in (a) - (d) must satisfy the following conditions to constitute an equilibrium:

(i) $p_{1}=D\left(Q_{1}+Q_{E}\right), Q_{1}=\int_{0}^{n s} q_{1}(i) d i, Q_{E}=\int_{0}^{n E} q_{E}(i) d i$ (markets clear in the first period).

(ii) $p_{2}=D\left(Q_{2}+Q_{L}\right), Q_{2}=\int_{0}^{n_{s}} q_{2}(i) d i, Q_{L}=\int_{0}^{n_{L}} q_{L}(i) d i($ markets 
clear in the second period).

(iii) If $n_{s}>0$, then $\left(q_{1}(i), q_{2}(i)\right)$ maximize $\left[p_{1} q_{1}+\delta p_{2} q_{2}-C\left(q_{1}, 0\right)-\right.$ $\left.\delta C\left(q_{2}, q_{1}\right)\right]$ with respect to $q_{1}, q_{2} \geq 0$ (staying firms maximize profits).

(iv) If $n_{E}>0$, then $q_{E}(i)$ maximizes $\left[p_{1} q-C(q, 0)\right]$ w.r.t. $q \geq 0$ (exiting firms maximize profits).

(v) If $n_{L}>0$, then $q_{L}(i)$ maximizes $\left[p_{2} q-C(q, 0)\right]$ w.r.t. $q \geq 0$ (late-entering firms maximize profits).

(vi) $\underset{q_{1}, q_{2} \geq 0}{\operatorname{Max}}\left[p_{1} q_{1}+\delta p_{2} q_{2}-C\left(q_{1}, 0\right)-\delta C\left(q_{2}, q_{1}\right)\right] \leq 0$ (further entry by staying firms is not strictly profitable).

(vii) $\underset{q \geq 0}{\operatorname{Max}}\left[p_{1} q-C(q, 0)\right] \leq 0$ (further entry by exiting firms is not strictly profitable).

(viii) $\underset{q \geq 0}{\operatorname{Max}}\left[p_{2} q-C(q, 0)\right] \leq 0$ (further entry by late-entering firms is not strictly profitable).

(ix) If $n_{s}>0$, then $\left[p_{1} q_{1}(i)+\delta p_{2} q_{2}(i)-C\left(q_{1}(i), 0\right)-\delta C\left(q_{2}(i), q_{1}(i)\right)\right]=$ $0,0 \leq i \leq n_{S}$ (zero profit for staying firms, if there are any ).

(x) If $n_{E}>0$, then $\left[p_{1} q_{E}(i)-C\left(q_{E}(i), 0\right)\right]=0,0 \leq i \leq n_{E}$ (zero profit for exiting firms, if there are any).

(xi) If $n_{L}>0$, then $\left[p_{2} q_{L}(i)-C\left(q_{L}(i), 0\right)\right]=0,0 \leq i \leq n_{L}$ (zero profit for late-entering firms, if there are any).

Conditions (vi) - (viii) ensure that there is no incentive for further entry (independent of what firms are already producing in the market) while (ix) - (xi) ensure that all active firms earn zero profit. Conditions (vi) - (viii) also ensure that no firm can make positive profit by behaving like some other type. No S-type firm can do better by exiting at the end of period 1 nor can an E-type firm make positive profit by staying on till period 2 (even if there are no S-type firms in the market) and so forth. This also ensures sequential rationality on the part of the E-type and S-type firms, who might otherwise find it advantageous to change their second-period behavior halfway through the evolution of the industry.

In an equilibrium with exit, an exiting firm makes zero profits in the first period, and in an equilibrium with late entry, a late entrant makes zero profits in the second period. A frm with no experience behaving optimally 
during the single period in which it remains in the market makes zero profits if and only if the market price equals its minimum average cost. The effective marginal cost of a firm which remains in the industry for only one period equals its marginal cost. A firm exiting in the end of the first period does not have incentive to overproduce in that period in order to reduce its costs, and thus increase profits in the second period.

These requirements for rational and competitive behavior on the part of the firms imply a number of restrictions on equilibrium outcomes, which are summarized in Proposition 1. 
PROPOSITION 1. In any equilibrium, the price in the first period is at most the minimum average cost for a firm with zero experience, and if there is exit in the equilibrium, the first-period price exactly equals the minimum average cost. All exiting firms earn zero profits in the first period. All staying firms earn strictly negative profits in the first period and strictly positive profits in the second period. If there exist late-entering firms, the secondperiod price is the minimum average cost for a firm uith zero experience. In any equilibrium, no firm praduces output in the range of strongly diminishing returns. ${ }^{6}$

In the model's notation:

1. $p_{j} \leq p_{m}<P(0), j=1,2$.

2. $n_{S}>0, Q_{1}>0$ and $Q_{2}>0$.

3. For all $i \in\left[0, n_{S}\right],\left[p_{1} q_{1}(i)-C\left(q_{1}(i), 0\right)\right]<0$ and $\left.\left[p_{2} q_{2}(i)-C\left(q_{2}(i), q_{1}(i)\right)\right]\right\rangle$ 0 .

4. If $n_{E}>0$, then $Q_{E}>0, p_{1}=p_{m}$ and for $i \in\left[0, n_{E}\right], q_{E}(i) \in\{q$ : $\left.[C(q, 0) / q]=p_{m}\right\}$.

5. If $n_{L}>0$, then $Q_{L}>0, p_{2}=p_{m}$ and for $i \in\left[0, n_{L}\right], q_{L}(i) \in\{q$ : $\left.[C(q, 0) / q]=p_{m}\right\}$.

6. $q_{1}, q_{2}, q_{E}, q_{L} \leq k$.

7. Either $\eta_{E}>0$ or $\eta_{L}>0$, but not both.

\footnotetext{
- Footnote 4 noted that in Assumption (A2), instead of $C_{B}(g, x)<0$, we could have assumed that $C(g, x)<C(g, 0)$ for all $x>0$. In that case Proposition 1 would require modification because it might happen that equilibrium profits for staying firms would be zero in both periods and that the effective marginal cost might be equal to the first period current marginal cost.
} 
Proof. Recall that $p_{m}=\operatorname{Min}\{[C(q, 0) / q]: q \geq 0\}$. Conditions (iv), (v), (x) and (xi) imply that if in an equilibrium we have $n_{E}>0$, then $p_{1}=p_{m}$ and $q_{E}(i) \in\left\{q: C(q, 0) / q=p_{m}\right\}$. Similarly, if $n_{L}>0$ then $p_{2}=p_{m}$ and $q_{L}(i) \in\left\{q: C(q, 0) / q=p_{m}\right\}$.

Conditions (vii) and (viii) also imply that $p_{i} \leq p_{m}, i=1,2$. From asoumption (A6), we have $P(0)>p_{m}$ and $s 0$ in any equilibrium it must be true that $p_{i}<P(0)$. It follows that $Q_{1}+Q_{E}=D\left(p_{1}\right)>0$ and $Q_{2}+Q_{L}=D\left(p_{2}\right)>0$.

To prove part (6) of Proposition 1, it is sufficient to consider the case of the staying firms. Suppose $q_{t}>K$ for some $t$. In equilibrium, a firm's lifetime profit is zero, so

$$
0=p_{1} q_{1}+\delta p_{2} q_{2}-f\left(q_{1}, q_{2}\right)<p_{1} q_{1}+p_{2} q_{2}-f\left(\alpha q_{1}, \beta q_{2}\right)-f\left((1-\alpha) q_{1},(1-\beta) q_{2}\right),
$$

for some $\alpha, \beta$ in $[0,1]$, using assumption (A5). The rightmost expresaion, can be rewritten as

$$
\left[p_{1} \alpha q_{1}+p_{2} \beta q_{2}-f\left(\alpha q_{1}, \beta q_{2}\right)\right]+\left[p_{1}(1-\alpha) q_{1}+\delta p_{2}(1-\beta) q_{2}-f\left((1-\alpha) q_{1},(1-\beta) q_{2}\right)\right]
$$

which is either zero or negative. In combination with the strong inequality in (3), this yields a contradiction, 80 it must be false that $q_{t}>K$ for some $t$.

Suppose $n_{E}>0$ and $n_{L}>0$. Then, $p_{1}=p_{2}=p_{m}$. This violates (vi) since by part (6) of Proposition 1, $C_{x}<0$, and facing those prices a firm could produce $g_{m}$ in each period and earn $\pi_{1}=0$ and $\pi_{2}>0$. Thus, $n_{E}>0$ and $n_{L}>0$ is impossible.

Now, suppose there is an equilibrium where $n_{S}=0$. Then, since $D\left(p_{\ell}\right)>$ $0, t=1,2$ in equilibrium implies that $n_{E}>0, n_{L}>0$, contradiction. So, in equilibrium, we must have $n_{S}>0$. This, in turn, can be used to show that $Q_{1}>0$ and $Q_{2}>0$. Suppose $Q_{1}=Q_{2}=0$. Then, $Q_{E}>0, Q_{L}>0$, i.e. $n_{E}>0, n_{L}>0$, a contradiction. Suppose, $Q_{1}=0, Q_{2}>0$. Then, $n_{E}>0$, i.e. $p_{1}=p_{m}$. Now if some S-type firm produces $q_{1}=0$, it earns a loss of $C(0,0)$. On the other hand if it produces $q_{1}=q_{m}>0$ (where $C\left(q_{m}, 0\right) / q_{m}=p_{m}$ ), then it has a lower cost function in period 2 while the current loss is zero. So producing $q_{1}=0$ cannot be profit maximizing. Thus, $q_{1}(i)>0$ for almost all $i \in\left[0, n_{s}\right]$, that is, $Q_{1}>0$, a contradiction. Similarly, $Q_{2}=0, Q_{1}>0$ is ruled out.

From the first order conditions of profit maximization for S-type firms it is clear that $p_{1}>C_{q}\left(q_{1}, 0\right)$ so that $q_{1}$ does not maximize period 1 profit at price $p_{1}$. 
Using condition (vii), we have that for all $i \in\left[0, n_{s}\right],\left[p_{1} q_{1}(i)-C\left(q_{1}(i), 0\right)\right]<0$ so that (ix) implies $\left[p_{2} q_{2}(i)-C\left(g_{2}(i), q_{1}(i)\right)\right]>0$.

Condition (iv) and (x) imply that if $n_{E}>0$, then for $i \in\left[0, n_{E}\right], q_{E}(i)>0$ and $\left[C\left(q_{E}(i), 0\right) / q_{E}(i)\right]=p_{m}$. Similarly, if $n_{L}>0$ then for $i \in\left[0, n_{L}\right], q_{L}(i)>0$ and $\left[C\left(q_{L}(i), 0\right) / q_{L}(i)\right]=p_{m} . / /$

If the fixed cost of production is zero, (i.e. $C(0, x)=0$ for all $x$ ), something not allowed by our assumptions, and if costs are convex, then a firm accumulates experience only in order to reduce its marginal cost. A well known result from standard price theory is that a competitive industry with increasing marginal costs, free entry, and no learning possibilities has no equilibrium if the fixed cost of production is zero. Loosely speaking, an infnite number of firms operate in the market, each producing an infinitesimal amount of output. This holds true even if firms are able to reduce their costs by accumulating experience.

There are two ways to understand this result. First, one can compare the situation to joint production. Imagine a firm that produces goods 1 and 2 jointly with cost function $f\left(q_{1}, q_{2}\right)=C\left(q_{1}, 0\right)+\delta C\left(q_{2}, q_{1}\right)$ and sells the two goods at prices $p_{1}$ and $\delta p_{2}$ respectively. Note that $f\left(q_{1}, q_{2}\right)$ is positive and strictly convex, and that $f(0,0)=0$ if the fixed cost is zero. A profit maximizing firm then chooses outputs at which the revenue hyperplane, $p_{1} q_{1}+\delta p_{2} q_{2}$, supports its cost function. For those maximum profits to be zero, the revenue hyperplane must pass through the origin. The unique point at which a hyperplane through the origin supports $f\left(q_{1}, q_{2}\right)$ with zero fixed cost is the origin itself. But then demand exceeds supply, and there is no equilibrium. Figure 2 illustrates this in two dimensions.

Second, the market outcome is socially efficient, as we will prove in Proposition 2 below. If it is efficient, it minimizes the discounted total cost 
of production, and therefore minimizes the average discounted cost of production for each firm. The cost curves are convex for each firm, and they would pass through the origin if there were no fixed cost. A property of an increasing convex cost function that goes through the origin is that the average cost is increasing in output. Output per firm should be as small as possible, so the social optimum would an infinite number of infinitesimal firms. As a result, the competitive equilibrium would not be finite either; it would fail to exist.

Thus, if costs are convex and fixed costs are zero, even with the possibility of learning, the peculiar result survives that an infinite number of firms operate in both periods, each period producing an infinitesimal amount. And thus, no learning ever takes place!

$s$

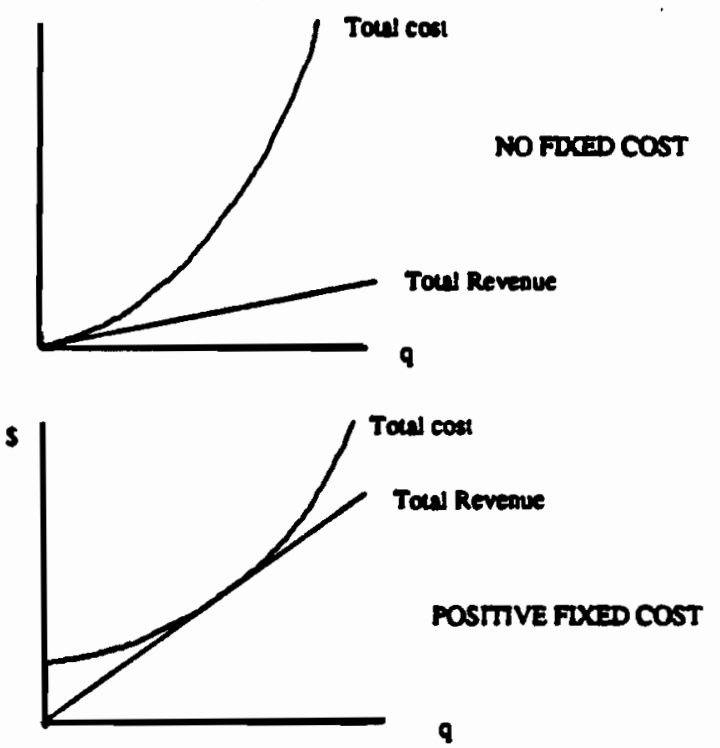

Figure 2: Nonexistence of Equilibrium

Even if an equilibrium were to exist, it is not clear whether it would be socially optimal in the context of learning, even if firms are price-takers. 
In equilibrium, initially identical firms may behave very differently, some staying, some exiting, and some entering late. A socially optimal allocation would solve the following problem:

\section{The Social Planner's Problem (SPP*):}

\section{Choose}

(a) ( $\left.n_{S}, n_{E}, n_{L}\right)$ : the measures of type S, E, and L firms who enter;

(b) Functions $q_{1}(i)$ and $q_{2}(i)$, where $q_{t}:\left[0, n_{s}\right] \rightarrow \mathbf{R}_{+}, t=1,2$, and $q_{t}($.$) is integrable with respect to Lebesque measure, q_{t}(i)$ being the output produced by staying firm $i$ in period $t$;

(c) Integrable functions $q_{E}:\left[0, n_{E}\right] \rightarrow \mathbf{R}_{+}$and $q_{L}:\left[0, n_{L}\right] \rightarrow \mathbf{R}_{+}$, where $q_{E}(i)$ and $q_{L}(j)$ are the output produced by the $i$-th $E$ and $j$-th I type firms, respectively, in their periods of operation;

so as to maximize

$$
\begin{aligned}
& \int_{0}^{Y_{1}} P(q) d q+\int_{0}^{Y_{2}} \delta P(q) d q-\int_{0}^{n_{s}}\left[C\left(q_{1}(i), 0\right)+\delta C\left(q_{2}(i), q_{1}(i)\right)\right] d i \\
& -\int_{0}^{n_{n}} E\left[C\left(q_{E}(i), 0\right)\right] d i-\delta \int_{0}^{n_{L}}\left[C\left(q_{L}(i), 0\right)\right] d i
\end{aligned}
$$

where $Y_{1}=Q_{1}+Q_{E}$ and $Y_{2}=Q_{2}+Q_{L}$, and

$$
Q_{1}=\int_{0}^{n_{S}} q_{1}(i) d i, \quad Q_{2}=\int_{0}^{n_{S}} q_{2}(i) d i, \quad Q_{E}=\int_{0}^{n_{E}} q_{E}(i) d i, \quad Q_{L}=\int_{0}^{n_{L}} q_{L}(i) d i .
$$

To maximize total surplus, the social planner is able to choose not only the number of firms in the industry each period, but also each individual firm's output each period. In choosing the latter, the social planner equates each individual firm's effective marginal cost to society's marginal benefit. But a social planner's choosing the number of staying firms, exiting firms, and late-entering firms turns out to be equivalent to setting each type's profits to zero. Furthermore, it turns out that in any efficient outcome the profits of staying firms are negative in the first period and positive in the second. Thus, the competitive market exactly reproduces the social planner's actions.

Under assumptions (A1) to (A6), not only does a competitive equilibrium exist, but it is unique in prices and it is socially optimal. 
PROPOSITION 2. Under assumptions (A1) to (A6), an equilibrium exists. It is unique in prices and aggregate output, and it is socially optimal.

Outline of the Proof . ${ }^{7}$ Consider the social planner's problem (SPP), defined above. The problem can be decomponed into two stages:

(i) For any vector of total output to be produced by different S,E and L type firms, the social planner decides on the minimum total cost of producing this vector by choosing the measure of active firms and their output.

(ii) The social surplus from any total output vector can be written as the area under the inverse demand curve and the social cost corresponding to that output, where the social cost function is defined in stage (i).

One can use a result from Aumann and Perles (1965) to show existence and characterize the social cost minimization problem in stage (i). The minimand in this problem is not necessarily convex (unless we assume [A7]) and there need not be a unique solution. Using the Lyapunov-Richter theorem, however, one can convexify the social cost possibility set generated by using a continuum of firms even though the individual firm's cost function is not necessarily convex. The social cost function (the value of the minimization problem) is therefore convex and differentiable. This makes the problem in stage (ii) a strictly concave maximization problem with a differentiable maximand.

Using a set of arguments based on the fact that $P(Q) \rightarrow 0$ as $Q \rightarrow+\infty$ and that the social marginal cost of output is bounded above zero, we can show that there exists a solution to the problem in stage (ii). As the maximand is strictly concave, the solution is unique (in terms of total output produced by different types of firms). The way the production of this output vector is organized depends on the cost minimization problem of stage (i). The inverse demand function generates a price in each period such that demand is equal to total output. The first order conditions for the social planner's maximization problem show that the price in each period is equal to the social marginal cost of production if a positive quantity is produced and the price is no greater than social marginal cost otherwise. The social marginal cost (for each of the types $E, S$ and $L$ ) is the Lagrangean multiplier for the appropriate social cost minimization problem in stage (i). One can show that in any solution to the social cost minimization problem, each firm produces

\footnotetext{
${ }^{7}$ A proof outline for Propositions 2 and 3 follows. The full proofs are available in the Appendix.
} 
output that maximizes its profit if the Lagrangean multipliers are interpreted as prices. Furthermore, such profit is zero if a positive quantity is produced and never exceeds zero. One can then establish that every solution to the SPP is sustainable as a competitive equilibrium. Also, the way the total output vector is produced in equilibrium can be shown to minimize social cost. Using the concavity of the eocial surplus in problem (ii) and the first order conditions of profit maximization, one can directly check that the competitive allocation indeed satisfies all the conditions of social optimality. Hence, a production plan is socially optimal if and only if it is sustainable as a competitive equilibrium. As there exists a solution to the SPP, there exists a competitive equilibrium. Furthermore, since the solution to the SPP is unique in total output produced, the competitive equilibrium is unique in prices.

If, in addition, we assume (A7), the social cost minimization problem in stage (i) becomes a convex problem, 80 it has a unique solution in the measure of active firms of different types and their output. So the competitive equilibrium allocation is unique in output and measure of active firms under (A7), which is what Proposition 3 says below.

\section{Further Results: The Case of Convex Costs}

Let us now introduce assumption (A7), convexity of the cost function, noting that (A7) does not necessarily imply (A5), which must still be retained. Earlier we saw that the equilibrium is unique in prices. When costs are convex, it is also unique in output and the number of firms.

The case of convex costs is the simplest special case one might wish to consider, but it yields quite interesting results in comparison with an industry which has no learning curve. In such an industry, identical firms produce the same output in equilibrium if the marginal cost curve is upward sloping, but when the opportunity for learning is added, identical firms behave differently in the same equilibrium.

PROPOSITION 3. Under assumptions (A1)-(A 7), the equilibrium (shown to exist and be efficient in Proposition 2) is unique in prices, individual firms' 
outputs in each period, and the number of firms. ${ }^{8}$

Convexity also allows us to be more specific about the properties of the equilibrium, as shown in the next set of propositions.

PROPOSITION 4. Under assumptions (A1)-(A7), the following is true in equilibrium:

(a) Each of the staying firms behaves identically, and there exists a positive measure of staying firms. There exist $q_{1}^{*}$ and $q_{2}^{*}$ such that $q_{1}^{*}(i)=q_{1}^{*}$ and $q_{2}^{*}(i)=q_{2}^{*}$ for all active staying firms $i$.

(b) If exiting firms exist, they produce at the minimum efficient scale of a firm with no experience, which is less than the $q_{1}$ produced by the staying firms. If $n_{E}>0$, then $q_{E}(i)=q_{m}$ for all $i \in\left[0, n_{E}\right]$, where $q_{m}$ is the unique solution to minimization of $[C(q, 0) / q]$ with respect to $q \geq 0$, and $q_{E}<q_{1}^{*}$.

(c) There exist no late-entering firms: $n_{L}=0 .^{0}$

Proposition 4 allows the unique equilibrium to take one of two distinct forms, depending on the cost and demand parameters: (i) with exit at the end of the first period, or (ii) without exit.

In an equilibrium with exit, some firms, after producing in the first period, decide to leave the industry. Thus, two types of firms coexist in the industry, those staying for both periods and those exiting at the end of the first period. Furthermore, firms that are identical ex ante nonetheless produce different outputs even in the first period. For a given price in period

\footnotetext{
An outline of the proof of Proposition 3 is included above immediately after Proposition 2. The full proof is available in the Appendix.

'The proof of Proposition 4 is available in the Appendix.
} 
1, exiting firms will produce less than staying firms, because overproducing to reduce future costs has no value for a firm that plans to exit at the end of the first period.

In an equilibrium without exit, all firms entering in the first period stay in the industry both periods (i.e. all are staying firms). Firms make losses today in order to accumulate experience, while they earn profits tomorrow on their maturity. To break even, the present value of the future profits must equal the losses today.

It is perhaps surprising that assumption (A7) is needed to ensure that there exist no late-entering firms in equilibrium. After all, a late-entering firm must compete with staying firms that have lower costs, and Proposition 1 showed that if late-entering firms do exist, it must be the case that the price is $p_{m}$ in the second period, so $p_{2}=p_{m}$ and the experienced firms are charging no more than than inexperienced firms. Example 1, in which costs are nonconvex, shows how this can happen.

\section{Example 1: Nonconvex Costs and Late Entry}

$D(p)=40-3 p$

$\delta=1$

$C(q, x)= \begin{cases}q^{2}+\left(4-\frac{x}{100}\right) & \text { for } x<3 \\ q^{2}+\frac{1}{(8 / 3) x-7} & \text { for } x \geq 3\end{cases}$

In Example 1, the learning is entirely in the fixed cost. The technology is nonconvex because the rate of learning increases at $x=3$, but it does satisfy assumption (A5), because decreasing returns set in at a large enough scale of operation. ${ }^{10}$

\footnotetext{
${ }^{10}$ The technology violates assumption (A1) because it is not continuous and differentiable, but it should be clear that the cost function could be smoothed without doing more than making the numbers less tidy.
} 
In equilibrium, $n_{S}=10, n_{E}=0, n_{L}=4, q_{1}=3, q_{2}=2, q_{L}=2, p_{1}=$ $10 / 3$, and $p_{2}=4$. These prices clear the market, because

$$
D\left(p_{1}\right)=40-3(10 / 3)=30=n_{S} q_{1}+n_{E} q_{E}=10(3)+0
$$

and

$$
D\left(p_{2}\right)=40-3(4)=28=n_{S} q_{2}+n_{L} q_{L}=10(2)+4(2) .
$$

The prices yield zero profits for the late-entering firms because $q_{m}=2$ and $p_{m}=4$. They yield zero profits overall for the staying firms because their profits are

$$
\begin{aligned}
\pi_{1}+\pi_{2} & =\left[p_{1} q_{1}-\left(q_{1}^{2}+4-\frac{\pi_{1}}{100}\right)\right]+\left[p_{2} q_{2}-\left(q_{2}^{2}+\frac{1}{(8 / 3) \varepsilon_{2}-7}\right)\right] \\
& =\left[(10 / 3)(3)-\left(3^{2}+4-0\right)\right]+\left[(4)(2)-\left(2^{2}+\frac{1}{(8 / 3)(3)-7}\right)\right]=-3+3 .
\end{aligned}
$$

Think of this from the point of view of a social planner. In the first period, he decides to introduce just a few firms, so that all of them can produce high output and acquire sufficient experience to cross the threshold for effective learning. In the second period, those firms cut back their output because further experience is not so valuable, but this means that for the social planner to satisfy demand he must introduce new firms.

Example 1 incidentally illustrates a point that will be generalized in Proposition 6: learning can make prices increase over time, even though costs are falling. This is because firms overproduce in the first period, incidentally driving down the price, in order to learn and save on their fixed costs later.

The discussion so far has shown that exit may occur in equilibrium, which makes the question of the efficiency of the market outcome especially interesting, because a firm that exits seems to waste its learning. Can it be socially efficient that some firms enter in the first period but never make any 
use of their first-period learning? Surprisingly enough, Propositions 2 and 3 tell us that the answer is yes. The unique equilibrium may involve some firms entering in the first period, producing a positive output and thereby reducing their costs, but then exiting before the second period. Their learning is wasted. Propositions 2 and 3 say that this is socially optimal- a social planner would also require that some firms exit and waste their learning rather than direct that there be fewer firms in period 1. Social optimality therefore does not imply the kind of "rationalization of industrial production" that governments favor when they try to consolidate firms in an industry.

With a little thought, it becomes clear why this can happen. Suppose that the marginal cost curve initially slopes steeply upwards at some production level $q^{\prime}$, so it is sharply convex, but that after a firm acquires experience, its marginal cost curve is closer to being linear. In the first period, it would be very expensive to serve market demand with firms producing much more than $q^{\prime}$. Therefore, the optimal plan is to have some firms produce only in the first period, to keep output per firm low then, but to have those firms exit in the second period, because the diseconomies of scale then become less severe.

A variable that will be important to the issue of exit is $\theta(x)$, the ratio of the quantity demanded to the minimum efficient scale when the price equals minimum average cost. Let us call this the natural dispersion, defined as

$$
\theta(x)=\frac{D\left(p_{m}(x)\right)}{g_{m}(x)},
$$

where

$$
q_{m}(x)=\operatorname{argmin}_{q}\{C(q, x) / q\}
$$

and

$$
p_{m}(x)=C\left(q_{m}(x), x\right) / q_{m}(x) .
$$


When the minimum efficient scale decreases with learning, the natural dispersion $\theta$ is increasing in $x$ : loosely speaking, the market is able to sustain more firms when firms are experienced than when they are not.

Proposition 5 gives general conditions under which there will be exit in equilibrium.

PROPOSITION 5. Under assumptions (A1)-(A7) and sufficiently heavy discounting, if the natural dispersion of the industry is less with positive than with zero experience, then exit will occur in equilibrium. If, on the other hand, the natural dispersion of the industry is greater with positive than with zero experience, then exit will not occur in equilibrium.

If $\theta(x)<\theta(0)$ for all $x>0$, there exists $\delta_{0}>0$ such that if $\delta \in\left(0, \delta_{0}\right)$, then $n_{E}>0$. If, on the other hand, $\theta(x)>\theta(0)$ for all $x>0$, there exists $\delta_{0}>0$ such that if $\delta \in\left(0, \delta_{0}\right)$, then $n_{E}=0$.

Proof. Suppose not. Then there exists sequence $\left\{\delta_{\ell}\right\} \rightarrow 0$ such that for all $t$, if the discount factor $\delta=\delta_{t}$, then no exit occurs in equilibrium. Let $\left(n_{t}, p_{1 t}, p_{2 t}, q_{1 t}, q_{2 t}\right)$ be the equilibrium (with no exit) corresponding to each $\delta_{t}$. Now, the sequences $\left\{p_{i t}\right\},\left\{q_{i t}\right\}, i=1,2$ are all bounded sequences (the prices lie in $\left[0, p_{m}\right]$ and the quantities in $\left.[0, K]\right)$. There exists a subsequence $\left\{t^{\prime}\right\}$ of $\{t\}$ such that the sequences of prices and quantities described above, converge to (say) $\left(p_{i}, q_{i} *\right), i=1,2$. From first order and zero profit conditions, we have that

$$
\begin{gathered}
p_{1 t^{\prime}}=C_{q}\left(q_{1 t^{\prime}}, 0\right)+\delta_{t} C_{x}\left(q_{2 t^{\prime}}, q_{1 t^{\prime}}\right) . \\
p_{2 t^{\prime}}=C_{q}\left(q_{2 t^{\prime}}, q_{1 t^{\prime}}\right) . \\
{\left[p_{1 t^{\prime}} q_{1 t^{\prime}}-C\left(q_{1 t^{\prime}}, 0\right)\right]+\delta_{t}\left[p_{2 t^{\prime}} q_{2 t^{\prime}}-C\left(q_{2 t^{\prime}}, q_{1 t^{\prime}}\right)\right]=0 .}
\end{gathered}
$$

Taking limits as $t \rightarrow \infty$ yields

$$
\begin{gathered}
p_{1}^{*}=C_{q}\left(q_{1}^{*}, 0\right), \\
p_{2}^{*}=C_{q}\left(q_{2}^{*}, q_{1}^{*}\right), \\
p_{i}^{*} q_{1}^{*}-C\left(q_{1}^{*}, 0\right)=0 .
\end{gathered}
$$


From (6) and (8) we have that

$$
p_{i}^{*}=p_{m}, q_{i}^{*}=q_{m} .
$$

By the definition of equilibrium, it must be true that firms earn non-negative profit in period 280 that for all $t^{\prime},\left[p_{2 t^{\prime}} q_{2 t^{\prime}}-C\left(q_{2 t^{\prime}}, q_{1 t^{\prime}}\right)\right] \geq 0$. Taking limits, we have that

$$
p_{2}^{*} q_{2}^{*}-C\left(q_{2}^{*}, q_{1}^{*}\right) \geq 0 \text {. }
$$

Combining (7) and (10), we can see that

$$
p_{2}^{*} \geq p_{m}\left(q_{1}^{*}\right), q_{2}^{*} \geq q_{m}\left(q_{1}^{*}\right) .
$$

Since $D\left(p_{1 t^{\prime}}\right) / q_{1 t^{\prime}}=D\left(p_{2 t^{\prime}}\right) / q_{2 t^{\prime}}$, we have after taking the limit as $t^{\prime} \rightarrow \infty$

$$
D\left(p_{1}^{*}\right) / q_{1}^{*}=D\left(p_{2}^{*}\right) / q_{2}^{*}
$$

From (9),

$$
D\left(p_{1}^{*}\right) / q_{1}^{*}=D\left(p_{m}\right) / q_{m}=\theta(0)
$$

From (11)

$$
D\left(p_{2}^{*}\right) / q_{2}^{*} \leq D\left(p_{m}\left(q_{1}^{*}\right)\right) / q_{m}\left(q_{1}^{*}\right)=\theta\left(q_{1}^{*}\right)
$$

But $\theta(0)>\theta\left(q_{1}^{*}\right)$ as $q_{1}^{*}=q_{m}>0$. Thus, (13) and (14) contradict (12).

Let us now turn to the case where $\theta(x)>\theta(0)$ for all $x>0$. Suppose Proposition 5 is false in this case. Then there exists a sequence $\left\{\delta_{i}\right\} \rightarrow 0$ such that exit occurs in equilibrium for all $i$. Let $\left(p_{1 i}, p_{2 i}, q_{1 i}, q_{2 i}, n_{i}\right)$ be the associated equilibrium prices, outputs and numbers of staying firms. Then $p_{1 i}=p_{m}$. Note that $\left\{\left(p_{1 i}, p_{2 i}, q_{1 i}, q_{2 i}\right)\right\}$ is a bounded sequence, converging to, say $\left\{\left(p_{1}, p_{2}, q_{1}, q_{2}\right)\right\}$. Abusing notation, let this be the convergent subsequence itself. Observe that

$$
p_{1 i}=p_{m}=C_{q}\left(q_{1 i}, 0\right)+\delta_{i} C_{z}\left(q_{2 i}, q_{1 i}\right) \text {. }
$$

Since $C_{x}\left(q_{2 i}, q_{1 i}\right)$ stays bounded as $i \rightarrow \infty$, we have $p_{2}=p_{m}\left(q_{1}\right)=p_{m}\left(q_{m}\right)$. (Note that $p_{m}(x)$ is continuous in $x$.) Observe that $p_{2 i}=C_{q}\left(q_{2 i}, q_{1 i}\right)$ and 80 , taking the limit, we have $p_{2}=C_{q}\left(q_{2}, q_{1}\right)=C_{q}\left(q_{2}, q_{m}\right)$. Since $p_{2}=p_{m}\left(q_{m}\right)$, we have $q_{2}=q_{m}\left(q_{m}\right)$. Lastly, note that for each $i$,

$$
\frac{D\left(p_{1 i}\right)}{q_{1 i}} \geq n_{i}=\frac{D\left(p_{2 i}\right)}{g_{2 i}}
$$

so that taking the limit we have

$$
\frac{D\left(p_{m}\right)}{q_{m}} \geq \frac{D\left(p_{m}\left(q_{m}\right)\right)}{q_{m}\left(q_{m}\right)}
$$


which is to say, $\theta(0) \geq \theta\left(g_{m}\right)$, a contradiction. //

If the market conditions are tight for firms with no experience, only a limited number of them are able to enter into the industry. Those firms overproduce initially in order to learn, thus suffering loseses in period 1, which they are able to recover later as they become inframarginal, with lower costs than potential entrants. If $\theta(x)>\theta(0)$, then the market can sustain more firms with experience than without experience. If learning decreases the marginal cost more or less uniformly for all levels of production, then we would not expect equilibria with exit even when there is little discounting. If, however, learning reduces marginal cost more for high levels of production, then if there is sufficiently little discounting, it may happen that there is exit in equilibrium. If, on the other hand, $\theta(x)<\theta(0)$, the second part of Proposition 5, then once firms acquire experience the market cannot sustain as many of them. Then, if discounting is sufficiently heavy, some firms are forced out in the second period.

To understand Proposition 5 in a different way, recall the joint production argument made earlier in connection with social optimality. Due to strict convexity of $f\left(q_{1}, q_{2}\right)$, given $p_{1}=p_{m}$, there exists a unique price in the market in period 2 such that a price taking firm who maximizes profits breaks even. The market in period 2 fails to sustain all those firms who become experienced by producing in period 1. The only way to reduce the number of firms entering in the first period is by increasing $p_{1}$. But this is impossible. Note that the equilibrium number of staying firms is given by $D\left(p_{2}\right) / q_{2}$. Then the additional demand in period 1 , i.e. $D\left(p_{m}\right)-\left[D\left(p_{2}\right) / q_{2}\right] q_{1}$ will be served by exiting firms each producing $q_{m}(0)$.

Proposition 5 has implications for the important special case in which the marginal cost of production shifts down uniformly with experience:

$$
C(q, x)=C_{v}(q)+q \phi(x)+F(x) .
$$


(Note that this specification also allows the fixed cost to fall with learning.) The function $q_{m}(x)$ is decreasing in $x$ for this case, so $F^{\prime}(x)<0$ and $C^{\prime}(x)<0$ for $x \in[0, K]$, and $\theta(x)>\theta(0)$ so Proposition 5 can be applied. Exit will not occur in equilibrium, if discounting is sufficiently heavy. ${ }^{11}$

Suppose, on the other hand, that learning reduces only the fixed cost. Then the minimum efficient scale decreases with experience, and $80 \theta(x)>$ $\theta(0)$ for all $x$, yielding Proposition 6.

PROPOSITION 6. If learning reduces only the fixed cost, then in equilibrium there is no exit, the price rises and each firm's output falls over time: $n_{E}=0, p_{1}<p_{2}$, and $q_{1}>q_{2}$.

This is the price path illustrated in Example 1. Effective marginal cost is always lower than the marginal cost of any experienced firm if learning reduces fixed cost alone. Thus, if $p_{1}>p_{2}$, then $q_{1}>q_{2}$, which contradicts the market equilibrium condition if later entry is impossible. Exit then does not occur because $p_{1}<p_{2} \leq p_{m}$. Thus, $n_{E}=0$. As we have seen, we cannot draw general conclusions about the properties of the price path, because it depends on the initial costs, the type and intensity of learning, the market demand, and the discount rate. The same is true for the quantity path of staying firms.

\footnotetext{
"The proof of the fact that $q_{m}(x)$ is decreasing in $x$ is as follows. $q_{m}(x)$ is defined by equating marginal to average cost, i.e. $C_{v}^{\prime}\left(q_{m}(x)\right)+\phi(x)=\frac{C_{v}\left(q_{m}(\varepsilon)\right)}{q_{m}(\varepsilon)}+\phi(x)+\frac{F(\varepsilon)}{q_{m}(\varepsilon)}$. This yields $C_{v}^{\prime}\left(q_{m}(x)\right) q_{m}(x)-C_{v}\left(q_{m}(x)\right)=F(x)$. Since $C_{v}$ is strictly convex, $C_{v}^{\prime}(q) q-C_{v}(q)$ is strictly increasing in $q$. If $F$ is decreasing in $x$, then $x_{1}>x_{2}$ implies $q_{m}\left(x_{1}\right) \leq q_{m}\left(x_{2}\right)$ and then $\theta(x)>\theta(0)$.
} 
Environments in which the equilibrium has exit are fully, if less intuitively, characterized in Proposition 7.

PROPOSITION 7. The following are necessary and sufficient conditions for an equilibrium to have exit. Let $\left(q_{1}^{*}, q_{2}^{*}\right)$ be the solution to the following minimization problem:

$$
z=\underset{q_{1}, q_{2} \geq 0}{\operatorname{Minimum}} \frac{C\left(q_{1}, 0\right)+\delta C\left(q_{2}, q_{1}\right)-p_{m} q_{1}}{\delta q_{2}}
$$

Under assumptions (A1)-(A7), an equilibrium with $n_{E}>0$ exists if and only if

$$
\left[D\left(p_{m}\right) / D(z)\right]>\left[q_{1}^{*} / q_{2}^{*}\right]
$$

Furthermore, if there exists an equilibrium with exit then $p_{2}=z, q_{1}=q_{1}^{*}, q_{2}=$ $q_{2}^{*}, n_{E}=\left[D\left(p_{m}\right)-n_{s}^{*} q_{i}^{*}\right] / q_{m}$.

Proof. We know that if exit occurs in equilibrium then $p_{1}=p_{m}$. Consider the following minimization problem:

$$
\underset{q_{1}, q_{2} \geq 0}{\operatorname{Minimize}}\left(1 / \delta q_{2}\right)\left[C\left(q_{1}, 0\right)+\delta C\left(q_{2}, q_{1}\right)-p_{m} q_{1}\right]
$$

It can be checked that there is a unique interior solution, say, $\left(q_{1}^{*}, q_{2}^{*}\right)$. Let $z$ be the value of the minimization problem. Then, one can easily check that:

$$
\begin{aligned}
& p_{m} q_{1}+z \delta q_{2}-C\left(q_{1}, 0\right)-C\left(q_{2}, q_{1}\right) \leq 0 \text { for all }\left(q_{1}, q_{2}\right) \\
& p_{m} q_{1}^{*}+z \delta q_{2}^{*}-C\left(q_{1}^{*}, 0\right)-C\left(q_{2}^{*}, q_{1}^{*}\right)=0 .
\end{aligned}
$$

Thus, the maximum profit earned by S-type firms is exactly zero if $p_{1}=p_{m}$ and $p_{2}=z$. So, in equilibrium with exit, $p_{2}=z$ and each firm produces $\left(q_{1}^{*}, q_{2}^{*}\right)$. Let $n_{s}^{*}=D(z) / q_{2}^{*}$. If there is an equilibrium with exit, then $n_{s}^{*} q_{j}^{*}<D\left(p_{m}\right)$ and $n_{S}^{*} q_{2}^{*}=D(z), 80$ that

$$
D\left(p_{m}\right) / D(z)>q_{1}^{*} / q_{2}^{*} \text {. }
$$

Thus, (15) is a necessary condition for an equilibrium with exit. Now, suppose (15) holds. Let $n_{E}^{*}=\left[D\left(p_{m}\right)-n_{S}^{*} q_{i}^{*}\right] / q_{m}>0$. It is easy to check that $\left(p_{1}=\right.$ $\left.p_{m}, p_{2}=z, n_{S}=n_{S}^{*}, n_{E}=n_{E}^{*}>0, q_{1}=q_{1}^{*}, q_{2}=q_{2}^{*}, q_{E}=q_{m}\right)$ is an equilibrium. /I 
Consider any cost function $C$ and the minimization problem indicated in the statement of Proposition 7. By definition of the minimum, it must be true that at prices $p_{1}=p_{m}$ and $p_{2}=z$, the firm can earn at most zero profit by producing in both periods. Obviously, $z<p_{m}$. Furthermore, check that the solution $\left(q_{1}^{*}, q_{2}^{*}\right)$ to this minimization problem is also a solution to the profit maximization problem of a staying firm facing prices $\left(p_{1}=p_{m}, p_{2}=z\right)$. The numbers $z, q_{1}^{*}$, and $q_{2}^{*}$ depend only on the cost function and have nothing to do with market demand. The proposition indicates that if $q_{1}^{*} \geq q_{2}^{*}$, there does not exist any downward sloping market demand function for which exit occurs in equilibrium. On the other hand, if $q_{1}^{*}<q_{2}^{*}$, exit occurs in equilibrium for any demand function $D$ which satisfies

$$
\frac{D\left(p_{m}\right)}{D(z)}>\frac{q_{1}^{*}}{q_{2}^{*}} .
$$

This is a restriction on the behaviour of the demand function at only two specific prices. Thus, for such cost functions the class of demand functions for which exit occurs in equilibrium is "large." The lower $q_{1}^{*}$ is relative to $q_{2}^{*}$, the larger the class of demand functions for which exit occurs.

\section{Examples and Implications}

Earlier we found two types of equilibria under convex costs: with and without exit. Under what cost and demand parameters will an equilibrium with exit arise? Example 2 helps develop some intuition for what may happen. In it, if the demand function is somewhat inelastic, then after the active firms reduce their costs in the first period by learning, their potential secondperiod output is so great that the market is then spoiled and some of them must exit. 
Example 2: Industry Dynamics Under Different Demand Parameters

$D(p)=20-b p$

$\delta=0.9$.

$C(q, x)=q^{2}\left(1+e^{-x}\right)+10$

Table 1 shows the equilibrium in Example 2 for two different values of the demand parameter, $b$.

If $b=1.3$, demand is weaker, and more elastic for prices with positive demand. In this case, there is no exit in equilibrium. All firms behave identically, producing higher output in the second period than in the first because of the reduction in costs from learning. Prices fall, for the same reason. Overall profits are zero, but they are negative in the first period and positive in the second period. The losses in the first period can be seen as the cost of learning, and the profits in the second period are quasi-rents on the acquired learning. Even though second-period profits are positive, no entry occurs, because an entrant would face higher costs, having never learned how to produce cheaply.

If $b=1$, demand is stronger, and less elastic for prices below 20/1.3. In this case, there is exit in equilibrium. The qualitative features of the staying firms are the same as when $b=1.3$ : output rises, prices fall, and profits go from negative to positive over time. When $b=1$, however, there are also exiting firms in the market. These firms operate only in the first period, during which they have zero profits, instead of the negative profits of the staying firms. Their higher profits arise because their outputs are smaller, but that means they acquire less learning than the staying firms, and cannot compete profitably in the second period. The "shakeout" which is the subject of Hopenhayn (1993) has occurred. 
TABLE 1:

THE EQUILIBRIUM IN EXAMPLE 2

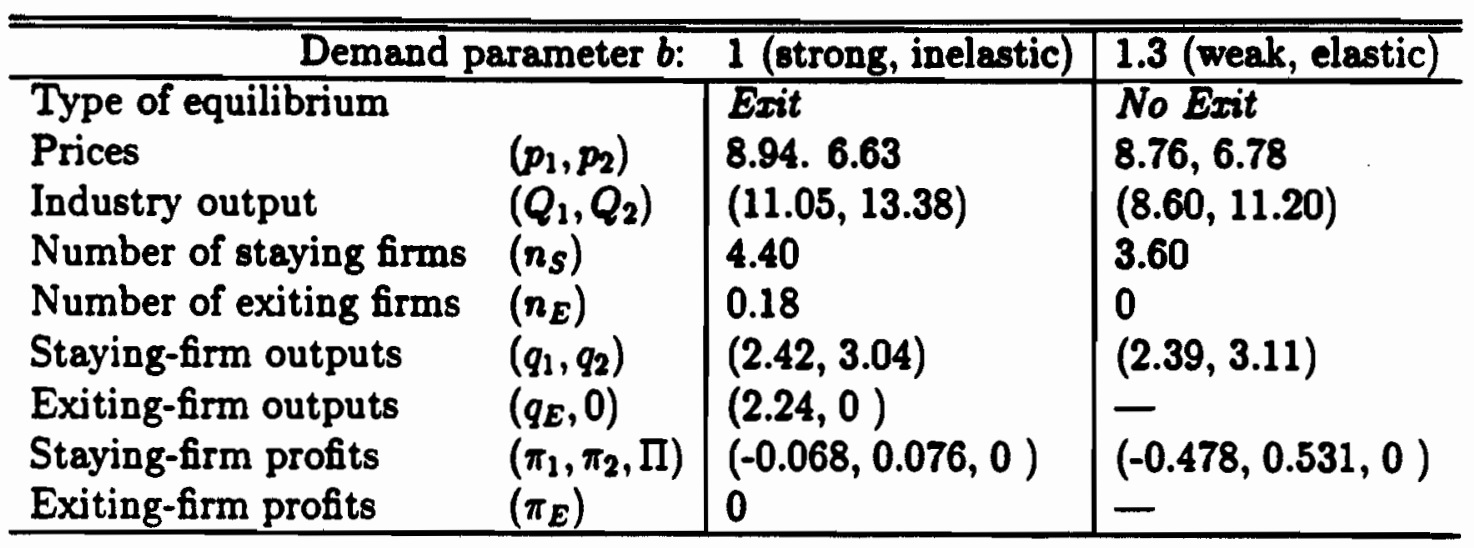

\section{Learning and Concentration}

Does learning-by-doing increase industry concentration? In an imperfectly competitive context, and without any learning in fixed costs, Dasgupta \& Stiglitz (1988, p. 247) say that, "... firm-specific learning encourages the growth of industrial concentration... Strong learning possibilities, coupled with vigorous competition among rivals, ensures that history matters..." Yet Lieberman (1982, p. 886) could find no systematic relation between learning by doing and industry concentration.

We have already found that history matters, even without the DasguptaStiglitz assumption of initial asymmetries, but Example 3 will show that the possibility of learning by doing can either increase or reduce concentration, depending on the particular industry. Empirical predictions must take into account the type of learning, not just the presence of learning. 


\section{Example 3: Industry Concentration}

$D(p)=1 / p$

$\delta=0.9$.

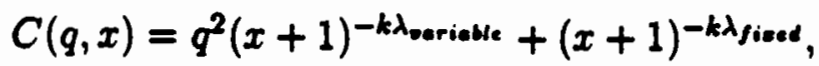

where $k$ represents the speed of learning, for $0<k<1$, and $\lambda_{\text {variable }}$ and $\lambda_{\text {fixed }}$ each take the value 0 or 1 to represent whether learning occurs in variable costs or fixed costs.

Let us denote as case (a) the case of learning in variable costs alone, where $\lambda_{\text {variable }}=1$ and $\lambda_{\text {fired }}=0$. Let us denote as case (b) the case of learning in fixed costs alone, where $\lambda_{\text {variable }}=0$ and $\lambda_{\text {fired }}=1$.

In both cases (a) and (b), if $k=0$ there is no learning and the cost function reduces to $C(q, x)=q^{2}+1$ and the equilibrium number of firms is $n=0.5$. As $k$ increases, learning-by-doing becomes stronger. The difference between the two cost functions is that in (a) learning affects only marginal cost, whereas in (b) it only affects the fixed cost.

Although $n=0.5$ when $k=0$, when $k=0.5$, the number of firms is 0.469 in case (a) and 0.553 in case (b). Thus, if learning influences mainly the marginal cost, it results in fewer and bigger firms, but if it reduces mainly the fixed cost it results in more and smaller firms. These are the results one would expect from simple price theory.

Further, as the speed of learning increases, industry concentration increases in case (a) and decreases in case (b). Finally, in both cases, consumers are enjoying lower prices as the speed of learning increases. The number of firms is greater in an industry with learning on fixed cost alone, however, than in an industry with no learning possibilities. Given that $p_{2}<p_{m}$, and that $p_{2}$ equals marginal cost (the same for all experience levels), we have that 
$q_{2}<q_{m}$. Hence, because no firm exits, the number of firms in the industry is $n=D\left(p_{2}\right) / q_{2}>D\left(p_{m}\right) / q_{m}$, which is the number of firms in an industry with no learning possibilities.

Antitrust authorities may learn an additional lesson from this model. Consider the following scenario, which is possible for a wide range of parameters. In the first period, big firms and small firms operate and charge high prices. In the second period, the big firms all reduce their prices, the small firms go out of business, unable to compete, and the big firms start earning strictly positive profits. An antitrust authority might look at this and infer predatory pricing. It is not; the big firms earn zero profits viewed ex ante, and the price drop is not strategic, but rather a consequence of falling costs. The exit of the small firms is socially optimal, and any punishment imposed on the big firms, or treble damages given to the small firms would reduce welfare.

\section{Concluding Remarks}

When so much of the teaching that microeconomic theorists do involves perfectly competitive partial equilibrium it is curious that so much of our research has focussed on imperfect competition. Perfectly competitive partia] equilibrium is by no means a closed subject, and there is more to be learned even about the models we teach our beginning students and use in everyday analysis. In particular, we still need a theory of endogenous market structure: why do firms in an industry behave differently at different points in its history, and why at any one time is heterogenous behavior observed?

One line of research, exemplified by Hopenhayn $(1992,1993)$, looks at the evolution of an industry in which firms encounter heterogeneous productivity shocks. Such shocks can explain why industries evolve over time, and 
why so much heterogeneity is observed even when firms are price takers and entry is free. We have come to the same general result that industries evolve and that firms behave heterogeneously, but for different reasons, and in a fully deterministic setting, but one with learning.

Our central purpose in this article has been to show that learning and perfect competition are easily compatible, and that learning has curious implications for the evolution of a competitive industry. We have shown that in the presence of convex learning, firms must enter at the beginning of an industry or never, and that the number of firms may decline predictably over time. Firms may behave differently even though they all begin with the same production opportunities. Some firms may enter at a small scale knowing full well that they will be forced to exit later; and these firms, in fact, will initially be the most profitable in the industry. Whether the equilibrium contains such firms or not, it will contain other firms which make losses in the first period and profits in the second. Viewing the situation from the second period, it may appear oligopolistic, because these firms will then be earning positive profits yet no entry will occur. Viewed from the start of the industry, however, these firms are merely reaping the returns to their early investments in learning, investments which potential entrants have not made.

This model has been quite general in some ways, but it is limited in others, and opportunities abound for extending the model. The main limitation of this model has been its restriction to two periods. By this simplification, we have been able to employ general cost and demand functions. Allowing such general functions is important in this context, because industry evolution can be different depending on the curvature of these functions. To specify linear demand, marginal costs, and learning would be to run the danger of missing important phenomena, something we conjecture is not true of limiting the model to two periods. The other limitation of the model is 
the assumption of convex costs used for the later propositions; in particular, the assumption that diminishing returns in learning and static production are greater than the effect of learning on marginal cost. This is certainly a reasonable case to consider, but it is not the only case. Convexity was not needed, however, to prove the existence, uniqueness, and optimality of equilibrium prices. Moreover, it is remarkable that the industry dynamics of entry and output are so rich even under convex costs; if the cost functions are less constrained, we would of course expect even more surprising results to be possible.

We have also shown that the competitive equilibrium is socially optimal. Learning does not necessarily destroy this conclusion of basic price theory. Even if the equilibrium involves some firms exiting early and not making use of the learning they acquired in the first period, this is socially optimal. This contrasts sharply with learning models which assume that marginal cost is constant in current output, because in those models the social planner would specify that the industry be a monopoly. Here, using standard U-shaped cost curves, monopoly is not optimal and no intervention is needed. 


\section{Appendix}

One of the implications of assumption (A5) is that the minimum one-period average cost with no learning, $p_{m}$, is attained at some finite positive output level. This is part of a more general lemma:

LEMMA I. Under assumptions (A1) - (A5), the functions $[C(q, 0) / q],[f(q, 0) / q]$ and $[f(0, q) / q]$ attain their minims at finite positive output levels.

PROOF. First note that since $C(0,0)>0$, the average costs in the statement of the lemma diverge to $+\infty$ as $q \rightarrow 0$.

Let $\left.m_{1}=\inf \{[f(q, 0) / q]: q \geq 0]\right\}$. Suppose the infimum is not attained at any finite $q$. Then, there exists $\left\{q_{n}\right\} \rightarrow+\infty$ such that $f\left(q_{n}, 0\right) / q_{n} \rightarrow m_{1}$ and, further, for each $n$,

$$
[f(q, 0) / q] \geq\left[f\left(q_{n}, 0\right) / q_{n}\right] \text { for } q \in\left[0, q_{n}\right]
$$

There exists $N$ such that $q_{n}>K$ for all $n \geq N$. Then, using (A5), for each $n \geq N$, there exists $z<q_{n}, y<q_{n}$ such that $z+y=q_{n}$ and: $f\left(q_{n}, 0\right)>f(z, 0)+f(y, 0)$, that is,

$$
\begin{aligned}
& f\left(q_{n}, 0\right) / q_{n}>[z /(z+y)][f(z, 0) / z]+[y /(z+y)][f(y, 0) / y] \\
& \geq[z /(z+y)]\left[f\left(q_{n}, 0\right) / q_{n}\right]+[y /(z+y)]\left[f\left(q_{n}, 0\right) / q_{n}\right]=f\left(q_{n}, 0\right) / q_{n},
\end{aligned}
$$

(using (16)), a contradiction.

A similar method can be used to show that $f(0, q) / q$ attains its minimum at a finite positive output. Lastly, note that (A5) implies that for any $q>K$, there exists $z, y \geq 0, z+y \leq q$,

$$
C(0,0)+\delta C(g, 0)>2 C(0,0)+\delta C(z, 0)+\delta C(y, 0)
$$

which implies

$$
C(q, 0)>C(z, 0)+C(y, 0)
$$

Again, the same set of steps can be replicated to show that $[C(q, 0) / q]$ attains its minimum at a finite positive level. //

PROPOSITION 2. Under assumptions (A1)-(A6), an equilibrium exists. It is unique in prices, and it is socially optimal. 
PROOF. Section III of the text defines the social planner's problem. Based on that definition, we can define the cocial cost minimization problem for any $Q_{1} \geq 0, Q_{2} \geq 0$ to be produced by S-type firms as:

$$
(S C M 1) \quad M \text { inimize } \int_{0}^{n s}\left[C\left(q_{1}(i), 0\right)+\delta C\left(q_{2}(i), q_{1}(i)\right)\right] d i
$$

w.r.t. $n_{S} \geq 0, q_{t}:\left[0, n_{s}\right] \rightarrow \mathbf{R}_{+}, t=1,2, q_{t}($.$) integrable w.r.t. Lebesgue measure,$ subject to the restrictions:

$$
\int_{0}^{n s} q_{t}(i) d i \geq Q_{t}, t=1,2
$$

Let $\psi\left(Q_{1}, Q_{2}\right)$ be the value of the minimization problem.

Similarly, if $Q_{E} \geq 0$ is the amount to be produced by E-type firms in period 1 , then the social cost minimization problem is given by:

$$
\text { (SCM2) Minimize } \int_{0}^{n_{E}} C(q E(i), 0) d i
$$

w.r.t. $n_{E} \geq 0, q_{E}:\left[0, n_{E}\right] \rightarrow \mathbf{R}_{+}, q_{E}($.$) integrable w.r.t. Lebesgue measure, subject$ to the restriction:

$$
\int_{0}^{n_{E}} q_{E}(i) d i \geq Q_{E}
$$

Let $\psi_{E}\left(Q_{E}\right)$ be the value of the minimization problem.

Lastly, if $Q_{L} \geq 0$ is the amount to be produced by L-type firms in period 2, then the social cost minimization problem is given by:

$$
\text { (SCM3) Minimize } \int_{0}^{n_{L}} \delta C\left(q_{L}(i), 0\right) d i
$$

w.r.t. $n_{L} \geq 0, q_{L}:\left[0, n_{L}\right] \rightarrow \mathbf{R}_{+}, q_{L}($.$) integrable w.r.t. Lebesgue measure, subject$ to the restriction:

$$
\int_{0}^{n_{L}} q L(i) d i \geq Q_{L}(*)
$$

Let $\psi_{L}\left(Q_{L}\right)$ be the value of this minimization problem.

First consider (SCM1). For $Q_{1}=Q_{2}=0$, the solution is obviously $n_{S}=0$. Suppose $Q_{2}=0$ and $Q_{1}>0$. Let

$$
m_{1}=\min \{[(C(q, 0)+\delta C(0, q)) / q]: q \geq 0\}
$$


From Lemms I we have the existence of finite $q>0$ which solves this minimization problem. Let $q\left(m_{1}\right)>0$ be any such solution. Consider the feasible set in (SCM1). One may without loss of generality confine attention to the subeet of the feasible set where $g_{2}(i)=0$ a.e. and

$$
\int_{0}^{n s} q_{1}(i) d i=Q_{1} \text {. }
$$

Let $\left(n_{s}, q_{1}(i), q_{2}(i)\right)$ be any such feasible colution. Then

$$
\begin{aligned}
\int_{0}^{n s}\left[C\left(q_{1}(i), 0\right)+\delta C\left(0, q_{1}(i)\right)\right] d i & \\
& =\int_{0}^{n s}\left[\left(C\left(q_{1}(i), 0\right)+\delta C\left(0, q_{1}(i)\right)\right) / q_{1}(i)\right] q_{1}(i) d i \\
& \geq \int_{0}^{n_{s} s} m_{1} q_{1}(i) d i \\
& =m_{1} Q_{1} \\
& =\left[C\left(q\left(m_{1}\right), 0\right)+\delta C\left(0, q\left(m_{1}\right)\right)\right] \hat{n}
\end{aligned}
$$

where $\hat{n}=Q_{1} / q\left(m_{1}\right)$. $m_{1} Q_{1}$

Thus, there exists a solution to SCM1 for $Q_{1}>0, Q_{2}=0$ and $\psi\left(Q_{1}, 0\right)=$

Similarly, let $m_{2}$ be defined by

$$
m_{2}=\min \{[(C(0,0)+\delta C(q, 0)) / q]: q \geq 0\} .
$$

Using Lemma I, there exists a finite positive solution to the minimization problem in (18). Consider (SCM1) for the case where $Q_{1}=0, Q_{2}>0$. One can show by similar arguments as above, that there exists a solution to (SCM1) for this case and that $\psi\left(0, Q_{2}\right)=m_{2} Q_{2}$.

In fact, the same set of arguments will show that there exists solution to (SCM2) and (SCM3) and that $\psi_{E}\left(Q_{E}\right)=p_{m} Q_{E}$ and $\psi_{L}\left(Q_{L}\right)=\delta p_{m} Q_{L}$.

Lastly, consider (SCM1) for the case where $Q_{1}>0, Q_{2}>0$. First note that $\left(n_{S}=1, q_{1}(i)=Q_{1}, q_{2}(i)=Q_{2}\right)$ is a feasible solution. Let $N$ be defined by

$$
N=\left[C\left(Q_{1}, 0\right)+\delta C\left(Q_{2}, Q_{1}\right)\right] /[C(0,0)]
$$

Suppose there is a feasible solution $\left(n_{S}, q_{1}(i), q_{2}(i)\right)$ where $n_{S}>N$. Then

$$
\int_{0}^{n s}\left[C\left(q_{1}(i), 0\right)+\delta C\left(q_{2}(i), q_{1}(i)\right)\right] d i \geq n_{s} C(0,0)>N C(0,0)=\left[C\left(Q_{1}, 0\right)+\delta C\left(Q_{2}, Q_{1}\right)\right] \text {. }
$$


We may, therefore, without loss of generality confine attention to feasible points where $n s \leq N$. Given asoumption (A5), we may confine attention to feasible solutions where $g_{t}(i) \leq K, i=1,2$. Lastly, it would be wasteful to introduce an S-type firm which produces zero output in both periods. So, w.l.o.g. one can confine attention to feasible points where $g_{t}(i)>0$ for come $t$, for all $i \in\left[0, n_{S}\right]$.

Note that it is poesible to extend any function $g_{t}(i)$ on $\left[0, n_{s}\right]$ to an integrable function on $[0, N]$ by setting $g_{t}(i)=0$ for $i \in\left(n_{S}, N\right]$.

Let $I\left(q_{1}, q_{2}\right)=1$, if $q_{t}>0$ for come $t, q_{t} \leq K$ for $t=1,2$ and $I=0$ otherwise. One can rewrite (SCM1) for $Q_{1}, Q_{2} \gg 0$ as

$$
\left(S C M 1^{\prime}\right) \quad \text { Minimize } \int_{0}^{N} G\left[g_{1}(i), C\left(g_{2}(i)\right] d i\right.
$$

w.r.t. $g_{t}:[0, N] x[0, K], g_{t}($.$) integrable, subject to$

$$
\int_{0}^{N} g_{t}(i) d i \geq Q_{i}
$$

where $G: \mathbf{R}_{+}^{2} \rightarrow \mathbf{R}_{+}$is given by

$$
G\left(q_{1}, q_{2}\right)=C\left(q_{1}, 0\right)+\delta C\left(q_{2}, q_{1}\right) I\left(q_{1}, q_{2}\right) .
$$

Check that $G$ is a bounded function on $\mathrm{R}_{+}^{2}$ (bounded above by $(1+\delta) C(K, 0)$ ). A direct appeal to Theorem 6.1 in Aumann and Perles (1965) shows that there exists a solution to (SCM1'). This, in turn, implies that there exists a solution to (SCM1) for all $Q_{1}, Q_{2} \geq 0 .^{12}$

Let $\lambda_{1}$ and $\lambda_{2}$ be the Lagrangean multipliers associated with the constraints $\left({ }^{*}\right)$ in (SCM1). Then at any optimal solution $\left(n_{s}, q_{1}(i), q_{2}(i)\right)$ the necessary conditions

$$
q_{1}(i)>0 \text { implies } C_{q}\left(q_{1}(i), 0\right)+\delta C_{w}\left(q_{2}(i), q_{1}(i)\right)=f_{1}\left(q_{1}(i), q_{2}(i)\right)=\lambda_{1}\left(Q_{1}, Q_{2}\right),
$$

and

$$
q_{2}(i)>0 \text { implies } C_{q}\left(q_{2}(i), q_{1}(i)\right)=f_{2}\left(q_{1}(i), q_{2}(i)\right)=\lambda_{2}\left(Q_{1}, Q_{2}\right) \text {. }
$$

\footnotetext{
${ }^{12}$ R.J. Aumann and M. Perles (1965) "A Variational Problem Arising in Economics." Journal of Mathematical Analysis and Applications, 11: 488 - 503.
} 
We claim that $\psi\left(Q_{1}, Q_{2}\right)$ is a convex function on $\mathbf{R}_{+}^{2}$. Let us define the "costpossibility set" of any firm $i \in R_{+}$by

$$
f(i)=\left\{\left(q_{1}, q_{2},-y\right) q_{t} \geq 0, y \geq C\left(q_{1}, 0\right)+\delta C\left(q_{2}, q_{1}\right)\right\} \cup\{(0,0,0)\}
$$

(no-entry is equivalent to $(0,0,0)$ )

$f(i)$ is identical for all $i$. Let $F$ be the "cost-possibility set" of the social planner, i.e. the set of all output-cost combinations that are feasible for the social planner by using any number of S-type firms and any distribution of output across such firms. Thus, $F$ is the integral of the set-valued correspondence $f(i): \mathbf{R}_{+} \rightarrow \mathbf{R}_{+}$with respect to Lebesgue measure. A direct appeal to the Lyapunov-Richter theorem (see L.1.3 in A. Mas-Colell (1985)) shows that $F$ is a convex set. By definition of $\psi$ in (SCM1), $F$ is also the set of all $\left\{\left(Q_{1}, Q_{2},-Y\right): Y \geq \psi\left(Q_{1}, Q_{2}\right), Q_{t} \geq 0, t=1,2\right\}$. It is easily checked that convexity of $F$ implies that $\psi$ is a convex function on $\mathbf{R}_{+}^{2}$.

Next, we claim that $\psi$ is continuous on $\mathbf{R}_{+}^{2}$. Continuity on $\mathbf{R}_{++}^{2}$ follows from its convexity. Continuity on the border can be verified directly. For example, choose any sequence $\left\{Q_{1}^{m}, Q_{2}^{m}\right\} \rightarrow\left(Q_{1}, Q_{2}\right)$ such that $Q_{1}=0, Q_{2}>0$. Let $q\left(m_{2}\right)$ be a solution to the minimization problem in (17). Then

$$
m_{2} Q_{2}^{m}=\psi\left(0, Q_{2}^{m}\right) \leq \psi\left(Q_{1}^{m}, Q_{2}^{m}\right) \leq\left\{C\left(\left[\left(Q_{1}^{m} q\left(m_{2}\right)\right) / Q_{2}^{m}\right], 0\right)+\delta C\left(q\left(m_{2}\right),\right.\right.
$$

and $\left.\left.\left[\left(Q_{1}^{m} q\left(m_{2}\right)\right) / Q_{2}^{m}\right]\right)\right\}\left\{Q_{2}^{m} / q\left(m_{2}\right)\right\} \rightarrow m_{2} Q_{2}=\psi\left(0, Q_{2}\right)$ as $m \rightarrow+\infty$.

Since the left hand side of the inequality equals $m_{2} Q_{2}^{m} \rightarrow m_{2} Q_{2}=\psi\left(0, Q_{2}\right)$, we have that $\psi\left(Q_{1}^{m}, Q_{2}^{m}\right) \rightarrow \psi\left(0, Q_{2}\right)$. Similar arguments can be used when the limits $\left(Q_{1}, Q_{2}\right)$ of the sequence $\left\{Q_{1}^{m}, Q_{2}^{m}\right\}$ are such that $Q_{2}=0, Q_{1}>0$ and also when both $Q_{t}=0$.

Next we want to establish that the partial derivatives of $\psi\left(Q_{1}, Q_{2}\right)$ exist on $\mathbf{R}_{++}^{2}$. For any fixed $Q_{2}=z>0$, let $g\left(Q_{1}\right)=\psi\left(Q_{1}, z\right)$. We will show that $g$ is differentiable on $\mathbf{R}_{++}$.

Firstly, note that $g$ is a convex function and so its right and left hand derivatives exist. Furthermore,

$$
g_{+}^{\prime} \geq g_{-}^{\prime} \text {. }
$$

Let $\left(n_{s}, q_{1}(i), q_{2}(i)\right)$ be the optimal solution of (SCM1) at $\left(Q_{1}, z\right)$. For $\varepsilon>0$ small enough, consider the vector $\left(Q_{1}+\varepsilon, z\right)$. Let $\hat{q}_{1}(i)=q_{1}(i)+\varepsilon\left[q_{1}(i) / Q_{1}\right]$. Note that 
$\hat{q}_{1}(i)=0$ if $q_{1}(i)=0$. It is easy to check that $\left(n_{S}, \hat{q}_{1}(i), q_{2}(i)\right)$ is a feasible way to produce $\left(Q_{1}+\varepsilon, z\right)$. Thus,

$$
\begin{aligned}
& g\left(Q_{1}+\varepsilon\right)=\psi\left(Q_{1}+\varepsilon, z\right) \leq \int_{0}^{n s}\left[f\left(\dot{q}_{1}(i), q_{2}(i)\right)\right] d i \\
& =\int_{0}^{n s}\left[f\left(\left[q_{1}(i)+\varepsilon\left(q_{1}(i) / Q_{1}\right)\right], g_{2}(i)\right) d i\right.
\end{aligned}
$$

so that

$$
\begin{array}{ll}
g_{+}^{\prime}\left(Q_{1}\right) & =\lim _{\varepsilon \rightarrow 0}\left\{\left[g\left(Q_{1}+\varepsilon\right)-g\left(Q_{1}\right)\right] / \varepsilon\right\} \\
\left.-f\left(q_{1}(i), q_{2}(i)\right)\right\} d i . & \leq \lim _{c \rightarrow 0}(1 / \varepsilon) \int_{0}^{n s}\left\{f\left(\left[q_{1}(i)+\varepsilon\left(q_{1}(i) / Q_{1}\right)\right], q_{2}(i)\right)\right.
\end{array}
$$

(Use the dominated convergence theorem and note that in the last expression the term within curly brackets equals zero if $q_{1}(i)=0$.)

$$
g_{+}^{\prime}\left(Q_{1}\right)=\lim _{i \rightarrow 0}(1 / \varepsilon) \int_{0}^{n s}\left\{f\left(\left[q_{1}(i)+\varepsilon\left(q_{1}(i) / Q_{1}\right)\right], q_{2}(i)\right)-f\left(q_{1}(i), q_{2}(i)\right)\right\} I(i) d i
$$

where $I(i)=1$ if $q_{1}(i)>0$ and $I(i)=0$ otherwise.

Since $f\left(q_{1}, q_{2}\right)$ is differentiable and further using (19), we have from the above inequality that:

$$
\begin{aligned}
& g_{+}^{\prime}\left(Q_{1}\right) \leq \int_{0}^{n s} f_{1}\left(q_{1}(i), q_{2}(i)\right)\left[q_{1}(i) / Q_{1}\right] I(i) d i \\
& =\int_{0}^{n s}\left\{\left[\lambda_{1}\left(Q_{1}, z\right)\right] / Q_{1}\right\} q_{1}(i) d i(u s i n g(19)) \\
& =\lambda_{1}\left(Q_{1}, z\right) .
\end{aligned}
$$

By a similar argument one can show that:

$$
g_{-}^{\prime}\left(Q_{1}\right)=\lim _{\varepsilon \rightarrow 0}\left[g\left(Q_{1}\right)-g\left(Q_{1}-\varepsilon\right)\right](1 / \varepsilon) \geq \lambda_{1}\left(Q_{1}, z\right) .
$$

Thus (22) and (23) imply

$$
g_{+}^{\prime}\left(Q_{1}\right) \leq \lambda_{1} \leq g_{-}^{\prime}\left(Q_{1}\right)
$$

which combined with (21) yields

$$
g_{+}^{\prime}\left(Q_{1}\right)=g_{-}^{\prime}\left(Q_{1}\right)=\lambda_{1}
$$

that is, $g$ is differentiable at $Q_{1}$ and

$$
g^{\prime}\left(Q_{1}\right)=\psi_{1}\left(Q_{1}, Q_{2}\right)=\lambda_{1}\left(Q_{1}, Q_{2}\right)
$$


Note that at $Q_{2}=0, \psi\left(Q_{1}, Q_{2}\right)=m_{1} Q_{1}$ so that $\psi_{1}\left(Q_{1}, 0\right)=m_{1}$. Similar reasoning shows that given $Q_{1} \geq 0$, the partial derivative of $\psi$ w.r.t. $Q_{2}$ exists on $R_{++}$and is given by

$$
\psi_{2}\left(Q_{1}, Q_{2}\right)=\lambda_{2}\left(Q_{1}, Q_{2}\right)
$$

and, in particular, $\psi_{2}\left(0, Q_{2}\right)=m_{2}$.

As the partial derivatives of $\psi$ exist at each point in $\mathbf{R}_{++}^{2}$ and $\psi$ is convex, it follows that $\psi$ is continuously differentiable on $\mathbf{R}_{++}^{2}$ (Section 42, Theorem $\mathrm{D}$ and Section 44, Theorem $E$ in Roberts and Varberg [1973]).

We summarize the above discussion in the Lemma II:

Lemma II: (a) There exists a solution to the (SCM1), (SCM2) and (SCM3).

(b) For any $Q_{E} \geq 0, \psi_{E}\left(Q_{E}\right)=p_{m} Q_{E}$ and in the solution to (SCM2), $q_{E}(i) \in$ $\left\{g:[C(g, 0) / q]=p_{m}\right\}$

(c) For any $Q_{L} \geq 0, \psi_{L}\left(Q_{L}\right)=\delta p_{m} Q_{L}$ and in the solution to (SCM3), $q_{L}(i) \in$ $\left\{q:[C(q, 0) / q]=p_{m}\right\}$.

(d) For $Q_{1}=0, \psi\left(Q_{1}, 0\right)=m_{1} Q_{1}$ where $m_{1}>0$ is defined by (17); For $Q_{2} \geq 0, \psi\left(0, Q_{2}\right)=m_{2} Q_{2}$, where $m_{2}$ is defined by (18).

(e) $\psi$ is continuous and convex on $\mathbf{R}_{+}^{2}$;

(f) For any $\left(Q_{1}, Q_{2}\right) \geq 0$, there exists Lagrangean multipliers $\lambda_{1}\left(Q_{1}, Q_{2}\right), \lambda_{2}\left(Q_{1}, Q_{2}\right)$, such that the solution $\left(n_{S}, q_{1}(i), q_{2}(i)\right)$ to (SCM1) is characterized by (19) and (20).

(g) $\psi$ is continuously differentiable on $\mathbf{R}_{++}^{2}$ and its partial derivatives are given by $\psi_{t}\left(Q_{1}, Q_{2}\right)=\lambda_{t}\left(Q_{1}, Q_{2}\right), t=1,2 ;$ further, $\psi_{1}\left(Q_{1}, 0\right)=m_{1}$ and $\psi_{2}\left(0, Q_{2}\right)=$ $m_{2}$.

We now rewrite $\left(S P P^{*}\right)$ as the following problem (hereafter referred to as SPP)

$$
\underset{Q_{1}, Q_{2}, Q_{E}, Q_{L} \geq 0}{\text { Maximize }} W\left(Q_{1}, Q_{2}, Q_{E}, Q_{L}\right)
$$

where

$W\left(Q_{1}, Q_{2}, Q_{E}, Q_{L}\right)=\left\{S\left(Q_{1}+Q_{E}\right)+\delta S\left(Q_{2}+Q_{L}\right)-\psi\left(Q_{1}, Q_{2}\right)-\psi_{E}\left(Q_{E}\right)-\psi_{L}\left(Q_{L}\right)\right\}$ and $S(y)=\int_{0}^{y} P(q) d q$. 
Note that $S$ is a strictly concave function, continuous on $\mathbf{R}_{+}$, continuously differentiable on $\mathbf{R}_{++}$and $S^{\prime}(y)=P(y)$.

Thus, using Lemma II, $W$ is continuous and strictly concave on $\mathbf{R}_{+}^{4}$. Further, at any point $\left(Q_{1}>0, Q_{2}>0, Q_{E} \geq 0, Q_{L} \geq 0\right)$, the partial derivatives of $W$ w.r.t all arguments exist. In particular,

$$
\begin{array}{r}
\partial W / \partial Q_{1}=P\left(Q_{1}+Q_{E}\right)-\psi_{1}\left(Q_{1}, Q_{2}\right)=P\left(Q_{1}+Q_{E}\right)-\lambda_{1}\left(Q_{1}, Q_{2}\right) \\
\partial W / \partial Q_{2}=P\left(Q_{2}+Q_{L}\right)-\psi_{2}\left(Q_{1}, Q_{2}\right)=P\left(Q_{2}+Q_{L}\right)-\lambda_{2}\left(Q_{1}, Q_{2}\right) \\
\partial W / \partial Q_{E}=P\left(Q_{1}+Q_{E}\right)-\psi_{E}^{\prime}\left(Q_{E}\right)=P\left(Q_{1}+Q_{E}\right)-p_{m} \\
\partial W / \partial Q_{L}=\delta P\left(Q_{2}+Q_{L}\right)-\psi_{L}^{\prime}\left(Q_{L}\right)=\delta\left[P\left(Q_{2}+Q_{L}\right)-p_{m}\right] .
\end{array}
$$

Since $P(y) \rightarrow 0$ as $y \rightarrow+\infty$ and $p_{m}>0$, there exists $Q_{0}>0$, such that $\partial W / \partial Q_{E}<0$ for any $\left(Q_{1}, Q_{2}, Q_{E}, Q_{L}\right)$ where $Q_{E}>Q_{0}$ and $\partial W / \partial Q_{L}<0$ for $Q_{L}>Q_{0}$. Note that $\lambda_{2}\left(Q_{1}, Q_{2}\right)=C_{q}\left(q_{2}(i), q_{1}(i)\right) \geq \min \left\{C_{q}(q, x): 0 \leq q \leq\right.$ $K, 0 \leq w \leq K\}$. Using (A1) we can check that the minimum in the previous expression is actually attained at some $\left(q^{\prime \prime}, w^{\prime \prime}\right) \in[0, K] \times[0, K]$. Thus, for all $\left(Q_{1}, Q_{2}\right)$ such that $Q_{2}>0$, we have $\psi_{2}\left(Q_{1}, Q_{2}\right) \geq C_{q}\left(q^{\prime \prime}, h^{\prime \prime}\right)=h$ where, using (A2), we have $h>0$. So, there exists $Q^{8}>0$ such that $\partial W / O Q_{2}<0$ for $Q_{2} \geq Q^{8}$ . Let $\hat{Q}=\max \left(Q^{8}, Q_{0}\right)$. One can without loss of generality, rewrite SPP as

\section{Maximize}

$$
\underset{Q_{1} \geq 0, Q_{2}, Q_{E}, Q_{2} \in[0, Q]}{\operatorname{Maximize}} W\left(Q_{1}, Q_{2}, Q_{E}, Q_{L}\right)
$$

We claim there exists a solution to this maximization problem. Let $W *$ be the supremum of the maximand (which can be $+\infty$ ). Then, there exists a sequence $\left\{Q_{1}^{m}, Q_{2}^{m}, Q_{E}^{m}, Q_{L}^{m}\right\}, m=1,2, \ldots$, where $W\left(Q_{1}^{m}, Q_{2}^{m}, Q_{E}^{m}, Q_{L}^{m}\right) \rightarrow W^{*}$. Suppose $\left\{Q_{1}^{m}\right\}$ is bounded above. Then the sequence $\left\{Q_{1}^{m}, Q_{2}^{m}, Q_{E}^{m}, Q_{L}^{m}\right\}$ is bounded above and has a convergent subsequence, whose limit is the optimal solution, using continuity of $W$.

Now suppose that $\left\{Q_{1}^{m}\right\}$ is not bounded above; abusing notation somewhat, suppose that $\left\{Q_{1}^{m}\right\} \rightarrow+\infty$. Choose $M$ such that $Q_{1}^{M}>0$. Then for $m \geq M$,

$$
\psi_{1}\left(Q_{1}^{m}, Q_{2}^{m}\right) \geq \psi_{1}\left(Q_{1}^{M}, Q_{2}^{m}\right) \geq \inf \left\{\psi_{1}\left(Q_{1}^{M}, x\right): 0 \leq x \leq K\right\}=\Delta(\text { say }) .
$$

Let $f(x)=\psi_{1}\left(Q_{1}^{M}, x\right)$. There exists a sequence $\left\{x_{k}\right\} \in[0, K]$, wch that $f\left(x_{k}\right) \rightarrow$ $\Delta$. We claim that $\Delta>0$. To see this, consider a convergent subsequence of $\left\{x_{k}\right\}$, e.g. $\left\{x_{k}^{\prime}\right\} \rightarrow x *$. If $x *>0$, then from continuous differentiability of $\psi$ 
(implying continuity of partial derivatives) on $\mathbf{R}_{++}^{2}$, we have that $f\left(x_{n}\right) \rightarrow f(x *)=$ $\psi_{1}\left(Q_{1}^{M}, x *\right)=\lambda_{1}\left(Q_{1}^{M}, x^{*}\right)>0$. Suppose $x *=0$. Note that $\psi_{1}\left(Q_{1}^{M}, 0\right)=m_{1}$. For $\varepsilon>0, \psi_{1}\left(Q_{1}^{M}, \varepsilon\right) \geq\left[\psi\left(Q_{1}^{M}, \varepsilon\right)-\psi(0, \varepsilon)\right] / Q_{1}^{M}$ (using convexity of $\psi$ ) 80 that taking the limit as $\varepsilon \rightarrow 0$ (using the continuity of $\psi$ on $R_{+}^{2}$ and the fact that $\psi(0,0)=0$ ) yields:

$$
\lim _{\varepsilon \rightarrow 0} \psi_{1}\left(Q_{1}^{M}, \varepsilon\right) \geq \psi\left(Q_{1}^{M}, 0\right) / Q_{1}^{M}=m_{1}
$$

so that $\lim _{k^{\prime} \rightarrow+\infty} f\left(x_{k}^{\prime}\right)=\Delta>0$.

Since $Q_{1}^{m} \rightarrow+\infty$, there exists $M^{\prime}>0$ such that for $m \geq M^{\prime}, P\left(Q_{1}^{m}\right)<\Delta$. Thus, for $m \geq \max \left(M, M^{\prime}\right), P\left(Q_{E}^{m}+Q_{1}^{m}\right)<\psi_{1}\left(Q_{1}^{m}, Q_{2}^{m}\right)$ i.e. $\partial W / \partial Q_{1}<0$ when evaluated at $m$ large enough. This is a contradiction. Thus, $\left\{Q_{1}^{m}\right\}$ must be bounded above. The proof of existence is complete.

Note that since $W$ is strictly concave on $\mathbf{R}_{+}^{4}$, the solution to (SPP) is unique.

It is easy to check that assumption (A6) implies $P(0)>\psi_{E}^{\prime}(0)=p_{m}$ and $\delta P(0)>\psi_{L}^{\prime}(0)=\delta p_{m}$ which, in turn, is sufficient to assert that if $\left(Q_{1}, Q_{2}, Q_{E}, Q_{L}\right)$ solves (SPP) then $Q_{1}+Q_{E}>0$ and $Q_{2}+Q_{L}>0$. Further, it is impossible that in the optimal solution $Q_{t}=0$ for either $t=1$ or $t=2$ or both. Suppose $Q_{1}=0$ and $Q_{2}>0$. Now, consider the original form of the social planner's problem (SPP*). Since $Q_{1}+Q_{E}>0$, it must be true that $Q_{E}>0$. Then the social planner can easily reduce total cost by letting the existing $n_{S}$ firms of type $S$ (who currently produce zero in period 1) produce a total amount $Q_{1}=Q_{E}$ (setting $n_{E}=0$ ). The cost in period 1 is unchanged and that in period 2 is reduced (using assumption (A2)), a contradiction. Similarly, $Q_{1}>0, Q_{2}=0$ is ruled out as this implies $Q_{L}>0$ and total cost can be reduced by letting S-type firms (who currently produce nothing in period 2) produce a total amount $Q_{2}=Q_{L}$ (setting $n_{L}=0$ ). Lastly, if both $Q_{1}$ are equal to zero, then $Q_{E}>0, Q_{L}>0$. Suppose we let $\varepsilon$ be the measure of E-type firms that produce in period 2-i.e. convert them to S-type firms, reduce the number of L-type firms by $\varepsilon$ and transfer their output to these $\varepsilon$ S-type firms. Then it is easy to see that total costs are reduced, a contradiction. To summarize:

Lemma III: There exists a solution to SPP and, hence, (SPP*). The solution to the social planner's problem is unique in $\left(Q_{1}, Q_{2}, Q_{E}, Q_{L}\right)$. If $\left(Q_{1}^{*}, Q_{2}^{*}, Q_{E}^{*}, Q_{L}^{*}\right)$ is an optimal solution in total output produced by different "types" of firms then $Q_{1}^{*}>0, Q_{2}^{*}>0$.

Let us now write down the first order necessary conditions for $\left(Q_{1}^{*}, Q_{2}^{*}, Q_{E}^{*}, Q_{L}^{*}\right)$ 
to be an optimal solution to (SPP)

$$
\begin{aligned}
& P\left(Q_{1}^{*}+Q_{E}^{*}\right)=\psi_{1}\left(Q_{1}^{*}, Q_{2}^{*}\right)[\left.\lambda_{1}\left(Q_{1}^{*}, Q_{2}^{*}\right)\right] \leq \psi_{E}^{\prime}\left(Q_{E}^{*}\right)\left[=p_{m}\right] \\
& P\left(Q_{1}^{*}+Q_{E}^{*}\right)=p_{m} \text { if } Q_{E}^{*}>0 \\
& \delta P\left(Q_{2}^{*}+Q_{L}^{*}\right)=\psi_{2}\left(Q_{1}^{*}, Q_{2}^{*}\right)\left[=\lambda_{2}\left(Q_{1}^{*}, Q_{2}^{*}\right)\right] \leq \psi_{L}^{\prime}\left(Q_{L}^{*}\right)\left[=\delta p_{m}\right] \\
& P\left(Q_{2}^{*}+Q_{L}^{*}\right)=p_{m} \text { if } Q_{L}^{*}>0
\end{aligned}
$$

Define $p_{1}^{*}=P\left(Q_{1}^{*}+Q_{E}^{*}\right), p_{2}^{*}=P\left(Q_{2}^{*}+Q_{L}^{*}\right)$. Let $\left(n_{S}^{*}, n_{E}^{*}, n_{L}^{*}, q_{1}^{*}(i), q_{2}^{*}(i), q_{E}^{*}(i), q_{L}^{*}(i)\right)$ be the solutions to (SCM1), (SCM2), and (SCM3) associated with $\left(Q_{1}^{*}, Q_{2}^{*}\right), Q_{E}^{*}$ and $Q_{L}^{*}$ respectively.

We want to show that $\left[p_{1}^{*}, p_{2}^{*}, n_{S}^{*}, n_{E}^{*}, n_{i}^{*},\left(q_{1}^{*}(i), q_{2}^{*}(i), 0 \leq i \leq n_{S}^{*}\right),\left(q_{E}^{*}(i), 0 \leq\right.\right.$ $\left.i \leq n_{E}^{*},\left(q_{L}^{*}(i), 0 \leq i \leq n_{L}^{*}\right)\right]$ constitutes an equilibrium. Recall the conditions (i)-(xi) that define an equilibrium. By definition of the prices, conditions (i) and (ii) in the definition of equilibrium are satisfied. From (29) and (30) we have that $p_{1}^{*} \leq p_{m}, p_{2}^{*} \leq p_{m}$ which implies conditions (vii) and (viii) of the definition of equilibrium are satisfied. If $n_{E}^{*}>0$, then it must be the case that $Q_{E}^{*}>0$ so that (30) implies $p_{1}^{*}=p_{m}$ and from Lemma II(b) we have that $q_{E}^{*}(i)$ maximizes one period profit at price $p_{m}$ and the maximum profit is equal to 0 . Thus, conditions (iv) and ( $x$ ) of the definition of equilibrium are satisfied. Similarly (32) and Lemma II (c) imply that conditions (v) and (xi) are met. Since $n_{S}^{*}, Q_{1}^{*}, Q_{2}^{*}>0$, it just remains to show that conditions (iii) and (ix) are satisfied (condition (vi) then holds automatically). In other words, we need to show that $\left(q_{1}^{*}(i), q_{2}^{*}(i)\right)$ maximizes two period discounted sum of profits at prices $\left(p_{1}^{*}, p_{2}^{*}\right)$ and that this maximum is equal to 0 .

Consider (SCM1) at $\left(Q_{1}^{*}, Q_{2}^{*}\right)>0$. From (29) and (31) we have that $\lambda_{1}\left(Q_{1}^{*}, Q_{2}^{*}\right)=p_{1}^{*}, \lambda_{2}\left(Q_{1}^{*}, Q_{2}^{*}\right)=p_{2}^{*}$. Then $\left(\lambda_{1}=p_{1}^{*}, \lambda_{2}=p_{2}^{*}, q_{1}^{*}(i), q_{2}^{*}(i), n_{S}^{*}\right)$ minimizes the Lagrangean function:

$$
L=\int_{0}^{n_{s}} f\left(q_{1}(i), q_{2}(i)\right) d i+\lambda_{1}\left(Q_{1}-\int_{0}^{n_{s}} q_{1}(i) d i\right)+\lambda_{2}\left(Q_{2}-\int_{0}^{n_{2}} q_{2}(i) d i\right)
$$

with respect to $n_{S} \geq 0, \lambda_{j} \geq 0, q_{1}:\left[0, n_{S}\right] \rightarrow \mathbf{R}_{+}, q_{2}:\left[0, n_{S}\right] \rightarrow \mathbf{R}_{+}, q_{t}($.$) inte-$ grable.

Then it must, in particular, be true that given $\left(\lambda_{1}=p_{1}^{*}, \lambda_{2}=p_{2}^{*}\right)$, the vector $\left(n_{s}^{*}, q_{1}^{*}(i), q_{2}^{*}(i)\right)$ maximizes:

$$
\int_{0}^{n s}\left[p_{1}^{*} q_{1}(i)+p_{2}^{*} q_{2}(i)-f\left(q_{1}(i), q_{2}(i)\right)\right] d i
$$


with respect to $n_{S} \geq 0, q_{1}:\left[0, n_{s}\right] \rightarrow \mathbf{R}_{\mathbf{+}}, q_{2}:\left[0, n_{S}\right] \rightarrow \mathbf{R}_{\mathbf{+}}, q_{t}($.$) integrable. But$ this implies that (almost everywhere) and

(a) $\left(q_{1}^{*}(i), q_{2}^{*}(i)\right)$ maximizes $\left[p_{1}^{*} q_{1}+p_{2}^{*} q_{2}-f\left(q_{1}, q_{2}\right)\right]$ with respect to $\left(q_{1}, q_{2}\right) \geq 0$,

(b) $\left[p_{1}^{*} q_{1}(i)+p_{2}^{*} q_{2}(i)-f\left(q_{1}(i), q_{2}(i)\right)\right]=0$.

Proof of (a) is obvious (for otherwise we could increase the maximand by choosing a different value for $\left(q_{1}(i), q_{2}(i)\right)$ on a positive measure of firms. To see (b), suppose not. There are two poesibilities:

(1) $\left[p_{1}^{*} q_{1}(i)+p_{2}^{*} q_{2}(i)-f\left(q_{1}(i), q_{2}(i)\right)\right]<0$ in which case the maximand is increased by simply eliminating a positive measure of ouch firms (reducing $n s$ below $n_{S}^{*}$ ), a contradiction;

(2) $\left[p_{1}^{*} q_{1}(i)+p_{2}^{*} q_{2}(i)-f\left(q_{1}(i), q_{2}(i)\right)\right]>0$ in which case the maximand can be increased to $+\infty$ by setting $n_{S}=+\infty$ and letting all $j \geq n_{S}^{*}$ produce the same output vector $\left(q_{1}(i), q_{2}(i)\right)$, a contradiction as $r_{S}^{*}<\infty$.

This proves (b). (a) and (b) imply that conditions (iii) and (ix) in the defnition of equilibrium hold. We have therefore proved that:

Lemma IV: Every solution to the social planner's problem is implementable as a competitive equilibrium. In particular, let $\left(n_{S}^{*}, n_{E}^{*}, n_{L}^{*}, q_{1}^{*}(i), q_{2}^{*}(i), q_{E}^{*}(i), q_{L}^{*}(i)\right)$ be a solution to (SPP*) with associated total output $\left(Q_{1}^{*}, Q_{2}^{*}, Q_{E}^{*}, Q_{L}^{*}\right)$. Then, if $p_{1}^{*}=P\left(Q_{1}^{*}+Q_{E}^{*}\right), p_{2}^{*}=P\left(Q_{2}^{*}+Q_{L}^{*}\right)$, then $\left[p_{1}^{*}, p_{2}^{*}, n_{S}^{*}, n_{E}^{*}, n_{L}^{*},\left(q_{1}^{*}(i), q_{2}^{*}(i), 0 \leq i \leq\right.\right.$ $\left.n_{S}^{*}\right),\left(q_{E}^{*}(i), 0 \leq i \leq n_{E}^{*},\left(q_{L}^{*}(i), 0 \leq i \leq n_{L}^{*}\right)\right]$ is a competitive equilibrium.

Lemmas III and IV imply:

Lemma V: There exists an equilibrium.

Next, we show that every equilibrium is socially optimal. Let $\left[p_{1}^{8}, p_{2}^{8}, n_{S}^{8}\right.$, $\left.n_{E}^{8}, n_{L}^{8},\left(\hat{q}_{1}^{8}(i), q_{2}^{8}(i), 0 \leq i \leq n_{S}\right),\left(q_{E}^{8}(i), 0 \leq i \leq n_{E}^{8}\right),\left(q_{L}^{8}(i), 0 \leq i \leq n_{L}^{8}\right)\right]$ be a equilibrium. Let $\left(Q_{1}^{3}, Q_{2}^{3}\right)$ be total output produced by $S$-type firms in this equilibrium. From Lemms III, we have that $Q_{1}^{f}>0, Q_{2}^{8}>0$. Let $Q_{E}^{8}$ and $Q_{L}^{8}$ be the total quantity produced by $E$ and $L$ type firms in their period of stay.

Our first claim is that $\left(n_{S}^{8}, \hat{q}_{1}^{8}(i), q_{2}^{8}(i)\right)$ is a socially cost minimizing way of producing $\left(Q_{1}^{8}, Q_{2}^{8}\right)$ i.e. it solves (SCM1) given $\left(Q_{1}^{8}, Q_{2}^{8}\right)$. Suppose not. Then there 
exists $\left(\hat{n}, \hat{q_{1}}(i), \hat{q_{2}}(i)\right)$ which solves (SCM1) given $\left(Q_{1}^{\beta}, Q_{2}^{8}\right)$ and

$$
\psi\left(Q_{1}^{\&}, Q_{2}^{q}\right)<\int_{0}^{m_{s}^{8}} f\left(\dot{q}_{1} \$(i), q_{2}^{q}(i)\right) d i .
$$

The sum of total profits of all S type firms in equilibrium is zero. Therefore,

$$
\begin{aligned}
& 0=\int_{0}^{n_{s}^{8}}\left[p_{1}^{8} \hat{q}_{1}^{8}(i)+\delta p_{2}^{8} q_{2}^{8}(i)-f\left(\hat{q}_{1}^{8}(i), q_{2}^{8}(i)\right)\right] d i<p_{1}^{8} Q_{1}^{8}+\delta p_{2}^{8} Q_{2}^{8}-\psi\left(Q_{1}^{8}, Q_{2}^{8}\right) \text { (uving } \\
& =\int_{0}^{n}\left[p_{1}^{8} \dot{q}_{1}(i)+\delta p_{2}^{8} \hat{q}_{2}(i)-f\left(\hat{q}_{1}(i), \dot{q}_{2}(i)\right)\right] d i
\end{aligned}
$$

which implies, in turn, that there exists some $i$ for which $\left[p_{1}^{\beta} \hat{q}_{1}(i)+\delta p_{2}^{\delta} \hat{q}_{2}(i)-\right.$ $\left.f\left(\hat{q}_{1}(i), \hat{q}_{2}(i)\right)\right]>0$. But by definition of equilibrium, the maximum possible discounted sum of profit at prices $\left(p_{1}^{8}, p_{2}^{8}\right)$ is 0 . We have a contradiction. Hence,

$$
\left(Q_{1}^{8}, Q_{2}^{8}\right)=\int_{0}^{n_{s}^{8}} f\left(\hat{q}_{1}^{8}(i), q_{2}^{8}(i)\right) d i
$$

and $\left(n_{S}^{8}, \hat{q}_{1}^{8}(i), q_{2}^{8}(i)\right)$ does solve (SCM1) given $\left(Q_{1}^{8}, Q_{2}^{8}\right)$.

Next, suppose $n_{E}^{8}>0$. Then from Proposition $1, p_{1}^{p}=p_{m}$ and $q_{E}^{8}(i) \in\{q \geq$ $\left.0:[C(q, 0) / q]=p_{m}\right\}$ which means that total cost of production of $Q_{E}^{\delta}$ is equal to $p_{m} Q_{E}^{8}$ which is equal to $\psi_{E}\left(Q_{E}^{8}\right)$, i.e. $\left(n_{E}^{8}, q_{E}^{8}(i)\right)$ solves (SCM2) given $Q_{E}^{8}$. Similarly, one can show that if $n_{L}^{8}>0$, then $\left(n_{L}^{8}, q_{L}^{8}(i)\right)$ solves (SCM3) given $Q_{L}^{8}$.

Therefore, in equilibrium, total output $\left(Q_{1}^{8}, Q_{2}^{8}, Q_{E}^{8}, Q_{L}^{8}\right)$ produced by different types of firms are produced in the socially cost minimizing way. Let the total social welfare in equilibrium is equal to $W\left(Q_{1}^{\delta}, Q_{2}^{\&}, Q_{E}^{8}, Q_{L}^{8}\right)$, where the function $W$ is as defined before introducing problem (SPP). As noted earlier, $W($.$) is strictly$ concave on $\mathbf{R}_{+}^{4}$. The partial derivatives of $W$ exist at all $\left(Q_{1}, Q_{2}, Q_{E}, Q_{L}\right) \geq 0$, where $Q_{1}>0, Q_{2}>0$.

Suppose equilibrium is not socially optimal. Let $\left(Q_{1}^{*}, Q_{2}^{*}, Q_{E}^{*}, Q_{L}^{*}\right)$ maximize social weifare. Then,

$$
W\left(Q_{1}^{8}, Q_{2}^{s}, Q_{E}^{8}, Q_{L}^{8}\right)-W\left(Q_{1}^{*}, Q_{2}^{*}, Q_{E}^{*}, Q_{L}^{*}\right)<0 .
$$

From Lemma III, $Q_{1}^{*}>0, Q_{2}^{*}>0$. As noted above, $Q_{1}^{\&}>0, Q_{2}^{*}>0$. So strict concavity of $W$ implies

$$
\begin{aligned}
& W\left(Q_{1}^{8}, Q_{2}^{8}, Q_{E}^{8}, Q_{L}^{\$}\right)-W\left(Q_{1}^{*}, Q_{2}^{*}, Q_{E}^{*}, Q_{L}^{*}\right) \\
& \geq\left[\partial W\left(Q_{1}^{\beta}, Q_{2}^{8}, Q_{E}^{s}, Q_{L}^{8}\right) / \partial Q_{1}\right]\left[Q_{1}^{\beta}-Q_{1}^{*}\right] \\
& +\left[\partial W\left(Q_{1}^{s}, Q_{2}^{8}, Q_{E}^{8}, Q_{L}^{8}\right) / \partial Q_{2}\right]\left[Q_{2}^{8}-Q_{2}^{*}\right] \\
& +\left[\partial W\left(Q_{1}^{s}, Q_{2}^{8}, Q_{E}^{s}, Q_{L}^{\xi}\right) / \partial Q_{E}\right]\left[Q_{E}^{8}-Q_{E}^{*}\right] \\
& +\left[\partial W\left(Q_{1}^{\delta}, Q_{2}^{\delta}, Q_{E}^{\xi}, Q_{L}^{\xi}\right) / \partial Q_{L}\right]\left[Q_{L}^{\xi}-Q_{L}^{*}\right] \text {. }
\end{aligned}
$$


Note that:

$$
\begin{aligned}
\partial W\left(Q_{1}^{8}, Q_{2}^{8}, Q_{E}^{8}, Q_{L}^{8}\right) / \partial Q_{1} & =P\left(Q_{1}^{8}+Q_{E}^{8}\right)-\psi_{1}\left(Q_{1}^{8}, Q_{2}^{8}\right)=p_{1}^{8}-\lambda_{1}\left(Q_{1}^{8}, Q_{2}^{8}\right) \\
= & p_{1}^{8}-f_{1}\left(\hat{q}_{1}^{8}(i), q_{2}^{8}(i)\right)(\text { from }(19)) .
\end{aligned}
$$

As $Q_{1}^{8}>0, Q_{2}^{8}>0$, there exists positive measure of $i$ such that $\hat{q}_{1}^{8}(i)>0, q_{2}^{8}(i)>0$, so that the first order conditions of profit maximization (condition (iii) in definition of equilibrium) implies that right hand side of (37) is equal to zero, i.e.

$$
\partial W\left(Q_{1}^{\xi}, Q_{2}^{8}, Q_{E}^{8}, Q_{L}^{8}\right) / \partial Q_{1}=0 \text {. }
$$

Similarly, one can show that

$$
\partial W\left(Q_{1}^{8}, Q_{2}^{8}, Q_{E}^{8}, Q_{L}^{8}\right) / \partial Q_{2}=0 .
$$

Next note that, from Proposition $1, p_{1}^{8} \leq p_{m}$ so that $\partial W\left(Q_{1}^{8}, Q_{2}^{8}, Q_{E}^{8}, Q_{L}^{8}\right) / \partial Q_{E}=$ $p_{1}-\psi_{E}\left(Q_{E}^{s}\right)=p_{1}-p_{m} \leq 0$ and it is equal to zero if $Q_{E}^{s}>0$ (since $p_{1}^{8}=p_{m}$ ). Thus,

$$
\left[\partial W\left(Q_{1}^{\&}, Q_{2}^{\&}, Q_{E}^{\&}, Q_{L}^{\$}\right) / \partial Q_{E}\right]\left[Q_{E}^{\$}-Q_{E}^{*}\right] \geq 0 \text {. }
$$

Similarly, one can show that

$$
\left[\partial W\left(Q_{1}^{s}, Q_{2}^{8}, Q_{E}^{8}, Q_{L}^{8}\right) / \partial Q_{L}\right]\left[Q_{L}^{8}-Q_{L}^{*}\right] \geq 0 .
$$

From (36) , (39) - (42) we have $W\left(Q_{1}^{8}, Q_{2}^{8}, Q_{E}^{8}, Q_{L}^{8}\right)-W\left(Q_{1}^{*}, Q_{2}^{*}, Q_{E}^{*}, Q_{L}^{*}\right) \geq 0$ contradicting (35). The proof is complete. We have thus shown:

Lemma VI: Every competitive equilibrium is socially optimal.

Combining Lemmas (III) - (VI) yields Proposition 2.

PROPOSITION 3. Under assumptions (A1)-(A7), an equilibrium exists. It is unique in prices, output, and number of firms, and it is socially optimal.

Proof. It is sufficient to show that under (A7) there exists a unique solution to (SCM1), (SCM2) and (SCM3). Proposition 2 then implies the result. To see uniqueness in (SCM1) let $\left(n_{S}, q_{1}(i), q_{2}(i)\right),\left(n^{\prime}, q_{1}^{\prime}(i), q_{2}^{\prime}(i)\right)$ be any two optimal production plans producing $\left(Q_{1}, Q_{2}\right) \gg 0$. Let $N=\max \left(n_{S}, n^{\prime}\right)$. Suppose $n_{S}<n^{\prime}$. Then extend $q_{t}(i)$ to the entire interval $\left[0, n^{\prime}\right]$ by setting $q_{t}(i)=0$ for $i>n_{s}$. Then let $\hat{q}_{t}(i)=(1 / 2)\left[q_{t}(i)+q_{t}^{\prime}(i)\right], t=1,2$ be defined on $\left[0, n^{\prime}\right]$. It is easy to check that this is a feasible production plan for $\left(Q_{1}, Q_{2}\right)$. Further,

$$
\int_{0}^{n^{\prime}}\left[f\left(\hat{q}_{1}(i), \dot{q}_{2}(i)\right)\right] d i<\int_{0}^{n^{\prime}}(1 / 2)\left[f\left(q_{1}(i), q_{2}(i)\right)+f\left(q_{1}^{\prime}(i), q_{2}^{\prime}(i)\right)\right] d i=\psi\left(Q_{1}, Q_{2}\right),
$$


a contradiction. Uniqueness in (SCM2) and (SCM3) are similarly established. //

PROPOSITION 4. Under assumptions (A1)-(A7), the following is true in equilibrium:

(a) Each of the staying firms behaves identically, and there exists a positive measure of staying firms. There exist $q_{1}^{*}$ and $q_{2}^{*}$ such that $q_{1}^{*}(i)=q_{1}^{*}$ and $q_{2}^{*}(i)=q_{2}^{*}$ for all active staying frms $i$.

(b) If exiting frms exist, they produce at the initial minimum efficient scale, which is less than the $q_{1}$ produced by the staying firms. If $n_{E}>0$, then $q_{E}(i)=q_{m}$ for all $i \in\left[0, n_{E}\right]$, where $q_{m}$ is the unique solution to minimization of $[C(q, 0) / q]$ with respect to $q \geq 0$, and $q_{E}<q_{i}^{*}$.

(c) There exist no late-entering firms: $n_{L}=0$.

Proof. The first part of (a) and (b) follow immediately from strict concavity of the profit function for each type of firm. (Note that since the total amount $\left(Q_{1}, Q_{2}\right)$ produced by all S-type firms is always strictly positive, $\left(q_{1}^{*}, q_{2}^{*}\right)>0$.) The second part of (b) results from Proposition 1, because the negative first-period profits of the staying firms result from their high production for the sake of learning. It remains to show that $n_{L}=0$ for part (c).

Suppose that $n_{L}>0$. Then from Lemma II, $n_{E}=0$ and $p_{2}=p_{m}$. Under (A7), there exists a unique $q_{m}$ which minimizes $[C(q, 0) / q]$ over $q \geq 0$. So, $q_{L}(i)=$ $q_{m}$ and

$$
p_{2}=p_{m}=C\left(q_{m}, 0\right) / q_{m}=C_{q}\left(q_{m}, 0\right)
$$

Furthermore,

$$
D\left(p_{2}\right)=D\left(p_{m}\right)=n_{s} q_{2}^{*}+n_{L} q_{m}>n_{s} q_{2}^{*} .
$$

From first order condition of profit maximization for frms which produce in both periods we have that $C_{q}\left(q_{2}^{*}, q_{1}^{*}\right)=p_{2}=p_{m}$ and, therefore (using (A7), (43) and $\left.q_{1}^{*}>0\right)$

$$
q_{2}^{*} \geq q_{m} \text {. }
$$

Next we claim that the following inequality is true:

$$
C_{w}\left(q_{2}^{*}, q_{1}^{*}\right) q_{1}^{*}+C_{q}\left(q_{2}^{*}, q_{1}^{*}\right) q_{2}^{*}-C\left(q_{2}^{*}, q_{1}^{*}\right) \geq 0 .
$$

By convexity of $C$ on $\mathbf{R}_{+}^{2}$,

$$
C\left(q_{m}, 0\right)-C\left(q_{2}^{*}, q_{1}^{*}\right) \geq C_{q}\left(q_{2}^{*}, q_{1}^{*}\right)\left(q_{m}-q_{2}^{*}\right)+C_{w}\left(q_{2}^{*}, q_{1}^{*}\right)\left(0-q_{1}^{*}\right)
$$


which implies that $C_{w}\left(q_{2}^{*}, q_{1}^{*}\right) q_{1}^{*}+C_{q}\left(q_{2}^{*}, q_{1}^{*}\right) q_{2}^{*}-C\left(q_{2}^{*}, q_{1}^{*}\right) \geq C_{q}\left(q_{2}^{*}, q_{1}^{*}\right) q_{m}-C\left(q_{m}, 0\right)=$ $p_{2} q_{m}-C\left(q_{m}, 0\right)=\left[p_{2}-\left(C\left(q_{m}, 0\right) / q_{m}\right)\right]=0$ (using (43) ).

From the first order conditions of profit maximization for S-type firms and the fact that in equilibrium, the discounted sum of profits is zero, we have:

$$
C_{q}\left(q_{1}^{*}, 0\right) q_{1}^{*}+\delta C_{w}\left(q_{2}^{*}, q_{1}^{*}\right) q_{1}^{*}+\delta C_{q}\left(q_{2}^{*}, q_{1}^{*}\right) q_{2}^{*}-C\left(q_{1}^{*}, 0\right)-\delta C\left(q_{2}^{*}, q_{1}^{*}\right)=0 .
$$

Using (46) in the above equation we have:

$$
C_{q}\left(q_{1}^{*}, 0\right) q_{i}^{*}-C\left(q_{1}^{*}, 0\right) \leq 0
$$

which implies that

$$
q_{1}^{*} \leq q_{m}
$$

so that, from (45), we have $q_{1}^{*} \leq q_{2}^{*}$. Thus,

$$
n s q_{1}^{*} \leq n s q_{2}^{*} \text {. }
$$

From (44) and (48) we have

$$
D\left(p_{2}\right)>n_{s} q_{2}^{*} \geq n_{s} q_{1}^{*}=D\left(p_{1}\right)
$$

and so, $p_{1}>p_{2}=p_{m}$, which violates condition (vii) of the definition of equilibrium. // 


\section{References}

Arrow, Kenneth. "The Economic Implications of Learning by Doing." Review of Economic Studies. 29 (June 1962): 152-173.

R.J. Aumann and M. Perles. "A Variational Problem Arising in Economics." Journal of Mathematical Analysis and Applications. 11 (1965): 488 $-503$.

Bhattacharya, G. "Learning and the Behavior of Potential Entrants." Rand Journal of Economics. 15 (Summer 1984): 281-289.

Boldrin, M. and Scheinkman, J.A. "Learning by Doing, International Trade and Growth: A Noten in The Economy as a Complex Evolving System, edited by P. Anderson and K.J. Arrow, Santa Fe Institute Studies in the Sciences of Complexity, Addison Wesley, 1988.

Clarida, R.H. "Entry, Dumping and Shakeout." American Economic Review. 83 (March 1993): 180-202.

Cabral, L. \& M. Riordan. (1991), "Learning to Compete and ViceVersa," Working paper number 167 , University of Lisbon.

Clarke, F., M. Darrough and J. Heineke. "Optimal Pricing Policy in the Presence of Experience Effects." Journal of Business. 55: (October 1982): $517-530$.

Dasgupta P. and J. Stiglitz. "Learning-by-Doing, Market Structure and Industrial and Trade Policies." Oxford Economic Papers. 40 (June 1988): 246-268.

Fudenberg, D. and J. Tirole. "Learning-by-Doing and Market Performance." Bell Journal of Economics. 14 (Autumn 1983): 522-530. 
Ghemawat, P. and Spence, M. "Learning Curve Spillovers and Market Performance." Quarterly Journal of Economics 100 (1985 Supp.): 839-52.

Hopenhayn, Hugo. "Entry, Exit, and Firm Dynamics in Long Run Equilibrium." Econometrica. 60 (September 1992): 1127-1150.

Hopenhayn, Hugo. "The Shakeout." working paper, University of Pompeu-Fabra, March 8, 1993.

Jovanovic, B. and Lach, S. "Entry, Exit and Diffusion with Learning by Doing." American Economic Review. 79 (September 1989): 690-699.

Lucas, Robert. "On the Mechanics of Economic Development." J. Monetary Econ. 22 (July 1988): 3-42.

Majd, S. and Pindyck, R.S. "The Learning Curve and Optimal Production under Uncertainty." Rand Journal of Economics. 20 (Autumn 1989): 331-343.

Mas-Colell, A. (1985) The Theory of General Economic Equilibrium: $A$ Differentiable Approach. Cambridge University Press, Cambridge, England.

Mookherjee, D. and D. Ray "Collusive Market Structure under Learningby-Doing and Increasing Returns." Review of Economic Studies. 58 (October 1991): 993-1009.

Mookherjee, D. and D. Ray (1992) "Learning-By-Doing and Industrial Stucture: An Overview." in Theoretical Issues in Development Economics, ed. by B. Dutta, S. G., D. Mookherjee \& D. Ray, New Delhi: Oxford University Press .

Panzar, J. C. (1989) "Technological Determinants of Firm and Industry Structure" in Handbook of Industrial Onganization, Volume I, edited by R. Schmalensee and R.D. Willig, Elseviers Science Publishers B.V. 
Roberts, A. and D.F. Varberg (1973) Convex Functions, Academic Press, New York.

Romer, Paul. "Increasing Returns and Long-Run Growth." J.P.E. 94 (October 1986): 1002-37.

Schumpeter (1950) Capitalism, Socialism, and Democracy, 3rd edition, New York: Harper.

Smiley, R.H., and S.A Ravid. "The Importance of Being First: Learning Price and Strategy." The Quarterly Journal of Economics. 98 (May 1983): 353-362.

Spence M. "The Learning Curve and Competition." Bell Journal of Economics. 12 (Spring 1981): 49-70.

Spence M. (1986) "Cost Reduction, Competition, and Industry Performance." in Joseph Stiglitz and G. Frank Mathewson, New Developments in the Analysis of Market Structure, Cambridge, Mass: The MIT Press, pp. 475-515.

Stiglitz, J. "Price Rigidities and Market Structure." American Economic Review. 74 (May 1984): 350-355.

Stokey, N. (1986) "The Dynamics of Industry-Wide Learning," in W.P. Heller, R. M. Starr and D.A Starrett, Eds,Equilibrium Analysis: Essays in Honour of Kenneth J. Arrow, Vol. II, Cambridge: Cambridge University Press.

Stokey, N. (1988) "Learning by Doing and the Introduction of New Goods." Journal of Political Economy. 96 (August 1988): 701-718.

Tirole, J. (1988) The Theory of Industrial Organization, Cambridge, Mass: The MIT Press. 